\title{
Cost of Living Inequality during the Great Recession
}

\author{
David Argente and Munseob Lee* \\ University of Chicago ${ }^{\dagger}$
}

February 15, 2015

\begin{abstract}
Using detailed barcode level data, we construct income-group specific price indices for the period of 2004 to 2010. We find substantial differences across income groups arising mainly during the Great Recession. The annual cost of living inflation of the highest quartile has been on average 0.7 percentage points lower than that of the lowest quartile of the income distribution. The difference can be explained by the way consumers adjusted their shopping behavior to mitigate the crisis. We find that product quality substitution, a margin mostly available to richer households, is the main mechanism explaining the differences in cost of living inflation. Our evidence suggests that not accounting for these differences during economic downturns could lead to significant biases in the calculation of inequality and poverty measures.
\end{abstract}

JEL Classifications: D12; E31; E32

${ }^{*}$ We thank Fernando Alvarez, Erik Hurst, Anil Kashyap, Robert Lucas, and Joseph Vavra for their advice and support. The paper benefited from comments and suggestions by many others, including Bong Geun Choi, Jorge L. Garcia, Jessie Handbury, Sara Moreira, Roberto Robatto, Adriaan Ten Kate, Yike Wang, Chen Yeh, and seminar participants at the University of Chicago, IEA meeting, Washington University Graduate Student Conference, and the Midwest Macro meeting.

†Contacts: David Argente dargente@uchicago.edu; Munseob Lee munseob@uchicago.edu 


\section{Introduction}

For decades economists have tried to study the patterns of poverty and inequality focusing only on disparities in nominal income or nominal wages. Measures of real income inequality that account for differences in cost of living are, arguably, better measures of differences in standard of living. This dimension, however, has been largely ignored in the literature due to the difficulty of calculating cost of living indices at the income-group level or finer levels of disaggregation. If the cost of living differs across income groups, our estimates of poverty and inequality would be misleading, particularly during bad times, when the well-known upward bias in the CPI is larger. ${ }^{1}$ In this paper, we calculate income-specific price indices and show that high-income households have experienced lower cost of living inflation than low-income households during the Great Recession. We argue that the difference can be explained by the way they were able to cope with the recession by adjusting their shopping behavior.

A recent literature has shown that household shopping behavior changed in the Great Recession. Households changed the quality of items they buy and the stores where these purchases are made or simply took advantage of sales and coupons. However, the extent to which households can adjust along such margins may vary with income. For example, if poor households already used all available coupons before the recession then they would have little scope for increased coupon use while rich households might be able to save money with increased coupon clipping. Since households have different margins to adjust their shopping behavior, they face heterogeneous inflation rates. However, these changes in shopping behavior are not captured by the conventional price indices. This is because the BLS collects price information from the store, not from the consumer. Taking advantage of a large scanner database from consumers, we calculate a cost of living inflation rate across different income groups. Different from other price indices, we allow three different components

\footnotetext{
${ }^{1}$ See, for example, Chevalier and Kashyap (2011), Coibion et al. (forthcoming), Kryvtsov and Vincent (2014), and Watanabe et al. (2014).
} 
in the price index to vary with income: i) set of good consumed, ii) expenditure shares on each of the goods and iii) actual prices paid. The last variation captures changes in shopping behavior. For example, to buy one liter of milk at cheaper price, consumers can use coupons, go to different stores, or pick lower quality milk. These changes in shopping behavior only affect actual prices paid, which so far has not been measured by standard price indices.

From our income-specific price indices, we find substantial differences across income groups during the Great Recession. In our preferred specification, the annual cost of living inflation of the highest quartile of the income distribution has been 0.7 percentage points lower than that of the lowest quartile over 2004-2010. To see if the gap comes from different margins of shopping behavior across income groups, we investigate three major ways consumers can adjust when they suffer income declines. The first is shopping intensity, which includes the frequency at which they purchase, purchases of sale items, coupon usage, buying generic products and large sized items. The second is store switching; the reallocation of expenditures toward lower-price retailers. Finally, we investigate quality substitution; the reallocation of expenditures from high to low quality brands.

By approximating the price index in a regression and controlling these three margins one by one, we distinguish which mechanism causes the gap. We find that product quality substitution can explain most of the gap in the cost of living inflation. This is, richer households were better able to pay lower prices for the same category of goods by shifting their expenditures across brands, while lowincome households have less room left for quality substitution during downturns. This extra margin of adjustment for richer households allowed them to lower their cost of living inflation relative to poorer households during the Great Recession.

In order to rule out the possibility that our results arise from the change in the pricing behavior of firms and/or retailers, we compute measures of posted and effective inflation and show that, in response to local demand shocks, effec- 
tive prices, the prices actually paid by consumers, respond significantly more than posted prices by retailers. In addition, we provide evidence that retailers are not price discriminating in favor of richer consumers by disproportionately decreasing the prices of the goods they purchase.

In the last section, we provide evidence that the response of rich and poor households also differs when they suffer idiosyncratic shocks. Since householdspecific shocks, after controlling for aggregate conditions, are uncorrelated with firm's pricing decisions, we can rule out the possibility that the firm's decision is behind our results. Our findings suggest that higher income households are better at adjusting the quality of products they purchase also after facing an idiosyncratic income shock.

Our paper has implications on the measurement of real variables such as income and wealth as well as other economic indicators such as poverty rate and inequality. Our findings suggest that there could be a systematic bias in the measurement of real variables during the recession. This bias could greatly affect, for example, the allocation of social transfers such as food stamps and other means-tested programs.

Our work contributes to various strands of literature. First, our work relates to the studies focusing on the differences in the cost of living across households. Earlier work by Michael (1979), Hagemann (1982), and Garner et al. (1996) have focused on computing group-specific inflation rates. More recently, Hobijn and Lagakos (2005) explore inflation inequality across households in the U.S. and find that poor and non-poor people face different inflation rates. ${ }^{2}$ These studies, however, only allow the shares of expenditures of different products to vary across groups. In our work, taking advantage of a large scanner data collected at the consumer level, we use the actual price paid by each income group to calculate the price indices. The change in actual price paid captures how much consumers save by adjusting their shopping behavior.

\footnotetext{
${ }^{2}$ However, the average difference in inflation between poor and non-poor is small, less than 0.1 percentage points on average.
} 
Second, our work is also related to the large literature studying the heterogeneity of shopping behavior across income groups. ${ }^{3}$ Aguiar and Hurst (2007) find that poorer households shop more intensively and typically pay lower prices for identical products. Griffith et al. (2009), using a national representative sample of U.K. households in 2006, find that savings from sales and buying in bulk are of a similar order of magnitude to those from quality substitution and store switching. They also find that poor households mostly use quality substitution and bulk purchases to save. Our findings, in the United States during the Great Recession, show the importance of product quality substitution. We provide a direct measure of product quality substitution and store switching and show that richer households are more likely to adjust these margins after an income shock.

Finally, our work contributes to the growing literature studying how shopping behavior changes over the business cycle. McKenzie and Schargrodsky (2005) show that an increase in shopping search activity is found to be one of the most prevalent adjustment mechanisms used by consumers to cope with the 2002 Argentinean financial crisis. Recent work by Nevo and Wong (2014) document that households lowered their grocery bill during the Great Recession by increasing their shopping intensity (i.e. purchasing more on sale, larger sizes and generic products, increasing coupon usage, and shopping at discount stores). Similarly, Stroebel and Vavra (2014) also find changes in shopping intensity by home-owners after housing wealth shocks. Coibion et al. (forthcoming) find that inflation in the effective prices declines significantly with higher unemployment, while little change occurs in the posted price inflation. This difference, they argue, reflects the reallocation of household expenditures across retailers particularly by households at the highest income quintile. In contrast

\footnotetext{
${ }^{3}$ At the most disaggregated level, households pay different prices to buy exactly the same good. Kaplan and Menzio (2014), using data from Nielsen Homescan, find that the distribution of prices paid by households for the same bundle of goods is approximately Normal with standard deviation between $9 \%$ and $14 \%$. They find that half of the dispersion can be explained by differences in the expensiveness of the stores where households shop, while the other half is mostly due to differences in households' choices of which goods to purchase.
} 
to the work of Coibion et al. (forthcoming), and taking advantage of a larger panel data with much wider geographical coverage, we are able to calculate the income-group specific effective prices. Although we also find that store switching contributes to the decline of effective prices during the Great Recession, we find that the main mechanism explaining the cost of living inequality is product quality substitution.

The structure of the paper is as follows. Section 2 discusses the data used for the empirical analysis. Section 3 develops the income-specific price indices. Section 4 uses a reduced form approach to analyze the implication of shopping behavior on the cost of living inequality. Section 5 rules out the possibility that the pricing behavior of retailers and firms drives our result. Section 6 presents direct evidence of the changes in shopping behavior and provides cross-sectional evidence that quality substitution is the most important channel driving the differences across income groups. Section 7 discusses the implication of our result and Section 8 concludes.

\section{Data}

We use two datasets supplied by the Kilts-Nielsen Data Center at the University of Chicago Booth School of Business: the Homescan and the Retail Scanner dataset. In addition, we use the retail pricing data provided by Symphony IRI.

\subsection{Nielsen Homescan Dataset}

The dataset tracks the shopping behavior of 40,000-60,000 households every year from 2004 to 2010 in 54 Metropolitan Statistical Areas. Each panelist use in-home scanners to record their purchases. ${ }^{4}$ A 12-digit Universal Product Code (UPC) identifies the items purchased by panelists. The dataset contains around

\footnotetext{
${ }^{4}$ Nielsen offers a variety of incentives to join and stay active such as monthly prize drawings, gift points and regular sweepstakes. The incentives are designed to be non-biasing (i.e. Nielsen does not provide account-specific coupons out of concern for potential impact to natural purchase selection of outlets and products).
} 
1.6 million distinct UPCs grouped into 1,235 product modules covering from food to beauty aids and computer software. ${ }^{5}$ For each UPC, the data contain information on the brand, size, packaging, and a rich set of product features. If the good was purchased at a store covered by Nielsen, the price is set automatically to the average price of the good at the store during the week when the purchase was made. If not, the panelist directly enters the price. Detailed transaction information is reported for each product purchased (e.g. UPC code, quantity, price, deals, and coupons). We combine this information with the weight and volume of the product to compute unit values. Since our dataset lacks other measures of quality, we follow the industrial organization and the international trade literature and approximate quality with the unit values.

In addition, the dataset contains information about each trip the panelist makes to purchase (e.g. date, retailer, store, price, total dollars spent, etc.) and demographic variables (i.e. age, education, annual income, marital status, employment, etc.), which are updated annually. In our dataset, the household income distribution is approximately stable in our sample frame with a median household income of $\$ 50,000$. Projection weights are constructed by Nielsen to make the sample representative of the US population. Our data covers around 40 percent of all expenditures on goods in the CPI. ${ }^{6}$

\subsection{Nielsen Retail Scanner Dataset}

The dataset consists of nearly 76 billion observations of weekly prices, quantities, and store information generated by point-of-sale systems for about 40,000 individual stores across 371 Metropolitan Statistical Areas between January 2006

\footnotetext{
${ }^{5}$ Table 6 depicts the distribution of UPCs and expenditures across different product groups as defined by Nielsen. The table shows that our sample includes a wide set of goods including a few durable goods (i.e. cameras, flashlights, cookware, etc). Unfortunately, our data does not include other important durables or goods purchased online. Our results should be interpreted accordingly.

${ }^{6}$ Nielsen has a comprehensive program of dropping and replacing panelists that do not perform to minimum reporting standards. Currently, Nielsen retains about $80 \%$ of its active panel each year. Nielsen uses a stratified sampling design to ensure that the panel is demographically balanced.
} 
and December 2011. The dataset consists of approximately 1.4 million distinct products each of them identified by a 12-digit UPC. ${ }^{7}$ Each store has a unique identifier that allows us to track stores over time. The dataset represents roughly 30 percent of total U.S. expenditures on food and beverages and roughly 2 percent of total household consumption (Beraja et al. (2014)).

\subsection{IRI Symphony Retail Scanner Dataset}

The data set consists of weekly store data at the store-week-UPC level and includes prices and quantity data of drug stores and grocery stores across 50 metropolitan areas and 31 product categories. ${ }^{8}$ The dataset contains around 2.4 billion transactions from January 2001 to December 2011 representing roughly 15\% of household spending in the Consumer Expenditure Survey (Stroebel and Vavra (2014)). ${ }^{9}$ Each retailer reports the total dollar value of weekly sales and total units sold for each UPC. This information can be used to calculate the average retail price in a given week inclusive of retail features, displays and retailer coupons. The dataset also includes information about the volume of each UPC, which can be used to construct unit values.

\section{Income Specific Price Indices}

Our analysis begins by calculating income specific cost of living inflation rates using the Homescan dataset. In this section, we first provide some background

\footnotetext{
${ }^{7}$ Approximately 97 percent of the sales in the data come from food, drug and mass merchandising stores.

${ }^{8}$ These product categories include Beer, Carbonated Beverages, Coffee, Cold Cereal, Deodorant, Diapers, Facial Tissue, Photography Supplies, Frankfurters, Frozen Dinners, Frozen Pizza, Household Cleaners, Cigarettes, Mustard \& Ketchup, Mayonnaise, Laundry Detergent, Margarine \& Butter, Milk, Paper Towels, Peanut Butter, Razors, Blades, Salty Snacks, Shampoo, Soup, Spaghetti Sauce, Sugar Substitutes, Toilet Tissue, Toothbrushes, Toothpaste, and Yogurt. The dataset includes grocery and drug chain data involving approximately $25 \%-30 \%$ of consumer packaged good sales in a grocery store.

${ }^{9}$ All estimates and analysis in this paper, based on data provided by SymphonyIRI Group, Inc. are by the authors and not by SymphonyIRI Group, Inc. The dataset is discussed in more detail in Bronnenberg et al. (2008)
} 
on the cost of living concept, our measurement goal. Then, we explain how this concept is related to the price indices commonly used in the literature. We then illustrate how our price index deviates from them by explaining the assumptions we are able to relax with our dataset.

Konüs (1939) developed the cost of living index and defined it as the minimum expenditure required in comparison period $t$ to attain the same level of utility achieve in the base period normalized by the actual expenditure in the base period.

$$
\pi_{t}^{c}=\frac{\min _{q_{i, t}} \sum_{i} p_{i, t} \times\left. q_{i, t}\right|_{U=U_{0}}}{\sum_{i} p_{i, 0} \times q_{i, 0}}
$$

The cost of living index is a measurement objective and the BLS has long stated that it operates within the cost of living index framework to produce the CPI (BLS (1997)). The first order approximations to the cost of living index are the well known Laspeyres, Paasche and geometric mean indices. The current CPI belongs to this class of indices since it uses a geometric formula for most basic indices and a Laspeyres formula for the rest. These indices use fixed expenditure weights for a given basket of goods in a certain period of time and only allow prices to vary. The fact that these indices do not allow consumer choices of goods to vary in response to relative price changes leads to the wellknow substitution bias (see Boskin (1996)). ${ }^{10}$ This bias is likely to increase if the shopping effort of household increases. Griffith et al. (2009) document that the difference between posted and effective prices increases with shopping effort. Similarly, Burstein et al. (2004) document the large measurement error that emerged in the Argentinean CPI after households substituted toward low

\footnotetext{
${ }^{10}$ For example, the Laspeyres index, which keeps quantities fixed at the level consumed in the base periods is an upper bound of the true cost of living index since it assumes no substitution in response to changes in relative prices. By the same logic, the Paasche index, which keeps quantities fixed at the level consumed in the comparison period, is a lower bound of the cost of living index. Figure 8 in the Appendix plots the Laspeyres, Paasche and geometric mean indices and compares them to the CPI-U Food and Beverages. As shown in the figure, the Laspeyres lies above the CPI and the Paasche index below. As expected the geometric mean index with expenditure weights at the level consumed in the base period lies between the Laspeyres and the Paasche indices.
} 
quality goods in the aftermath of the 2001 Argentinean devaluation. And, more recently, Chevalier and Kashyap (2011) and Coibion et al. (forthcoming) show that this gap is counter-cyclical as shopping effort augments during downturns.

An alternative to mitigate the substitution bias is to compute a second order approximation to the cost of living index, also known as superlative indices. ${ }^{11}$ Indices such as the Tornqvist and the Fisher Ideal use both the current and base time period expenditure weights to reflect any choices consumers make in response to changes in relative prices. ${ }^{12}$ Another alternative is to use a Sato-Vartia price index since it also allows the expenditure weights to vary over time and it is theoretically justified if one assumes a CES utility function (Sato (1976); Vartia (1976)). In this paper we choose to present our results using a Sato-Vartia price index for comparability with the previous literature. However, all our results are robust to using other indices. The Sato-Vartia index is defined as follows:

$$
\pi_{t}=\prod_{j}\left(\frac{p_{j, t}}{p_{j, 0}}\right)^{w_{j, t}}
$$

This is the geometric mean of the price changes of a category of goods, in our case a product module, weighted by ideal log-change expenditure weights defined as follows

$$
\begin{gathered}
w_{j, t}=\frac{\frac{s_{j, t}-s_{j, 0}}{\ln s_{j, t}-\ln s_{j, 0}}}{\sum_{j}\left(\frac{s_{j, t}-s_{j, 0}}{\ln s_{j, t}-\ln s_{j, 0}}\right)} \\
s_{j, t}=\frac{p_{j, t} \times q_{j, t}}{\sum_{j} p_{j, t} \times q_{j, t}}
\end{gathered}
$$

where $p_{j, t}$ is the quantity weighted average unit price paid (i.e. price per liter of milk) by the households for product in category $j$ at time $t$ and $q_{j, t}$ is the total quantity purchased. The weights $w_{j, t}$ capture the willingness of households to substitute across product categories. Products that are highly substitutable may

\footnotetext{
${ }^{11}$ The study of these indices started from the seminal work of Diewert (1976)

${ }^{12}$ Figure 9 in the Appendix shows that the Tornqvist, Fisher Ideal, and Sato-Vartia calculated with the Homescan behave very similarly and lie below the CPI-U Food and Beverages.
} 
receive a much smaller weight than products whose share barely moves after a price change; these products get a weight close to their average expenditure share. ${ }^{13}$

Implementing superlative indices or a Sato-Vartia index to the CPI calculations has been difficult because the current expenditure weights are available only with a lag. Using the Nielsen Homescan datasets gives use several advantages over the BLS data. First, the availability of both prices and quantities in our dataset provides us with the necessary inputs to calculate superlative indices. Second, we can use the actual the price paid by the household as opposed to the posted price to calculate the price indices. Third, within each product category the number of products is much larger than the number of products used to calculate the CPI. And, fourth, we are able to use the demographic information of the buyers provided by the dataset to distinguish what each household is buying, where are they doing so, and how much are they paying for a given product.

Because the basket actually purchased by the lowest quartile of the income distribution differs from that of higher quartiles, the cost of living inflation faced by this group not only differs from that of the CPI but might also be very different from the one faced by richer groups. ${ }^{14}$ Therefore, in order to build incomespecific price indices we relax two standard assumptions of the literature. First, we build on the previous literature and allow the expenditure weights of our price index to be income group specific. Handbury (2013) shows, for example, that consumer expenditure shares vary systematically with income. And, second, we allow the price paid for a given product to be income group specific.

\footnotetext{
${ }^{13}$ The limit of $\frac{s_{j, t}-s_{j, 0}}{\ln s_{j, t}-\ln s_{j, 0}}$ when $s_{j, t} \rightarrow s_{j, 0}$ is $s_{j, 0}$.

${ }^{14}$ In Figure 7, we provide evidence that higher income households purchase different, more expensive products. The figure shows how much more or less each household pays per unit, for a product within a module, with respect to the mean household. The upward slope of the graph indicates that richer households pay more. In particular, households in the highest income category pay at least 6 percent more for products in the same module than households in the lowest income category. The relative prices are measured in a regression of log unit price paid against module, region, chain store, and quarter fixed effects. The log household income is plotted after controlling for demographic differences. Consistent with Handbury (2013), our results indicate that richer households buy more expensive products.
} 
Figure 1: Sato-Vartia Price Index with Income Specific Expenditure Weights

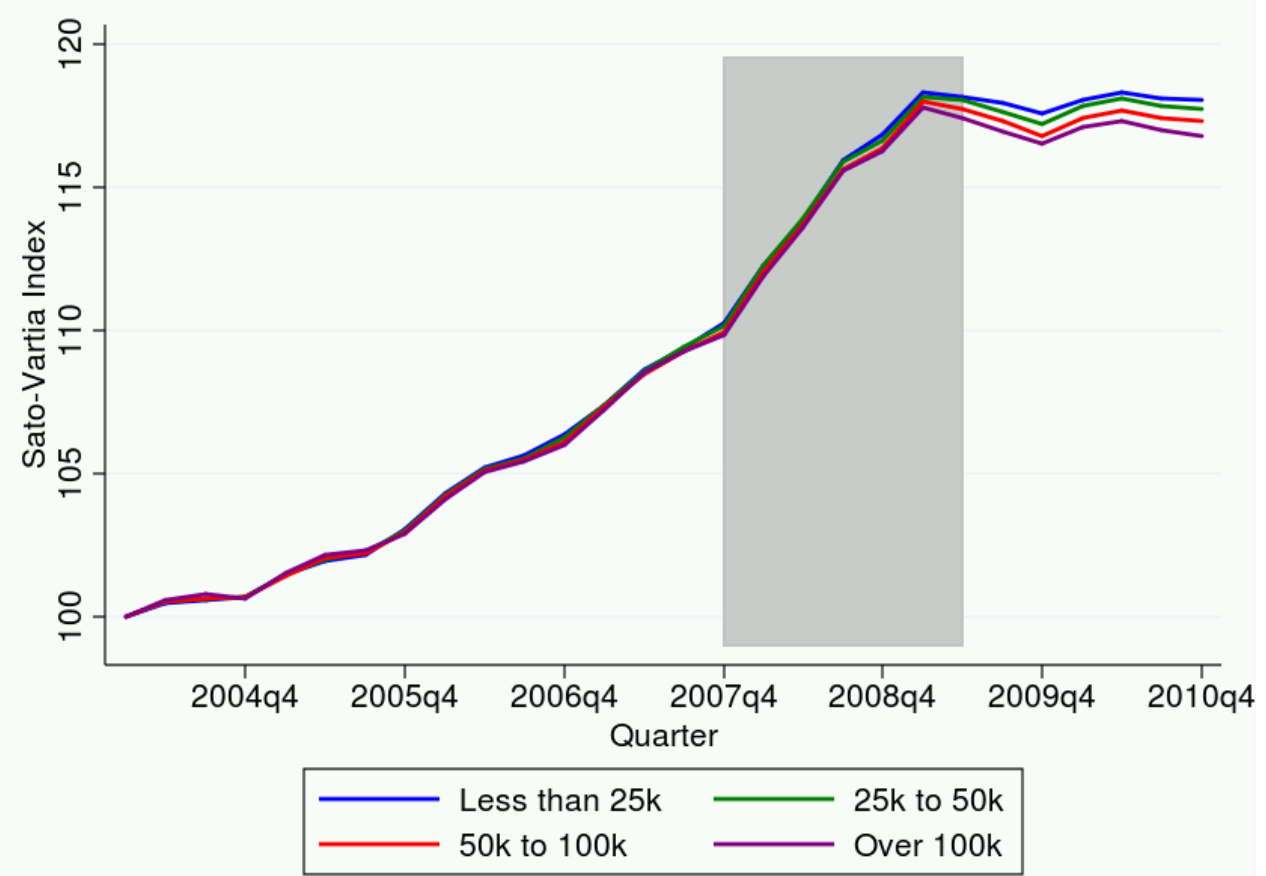

Note: The graph plots the Sato-Vartia index, from the first quarter of 2004 to the last of 2010, for each quartile of the income distribution. The expenditure weights are income specific. The indices are calculated at the quarterly frequency and at the product module level. The shaded areas indicate periods designated as recessions by the National Bureau of Economic Research. The source is the Nielsen Homescan.

By doing this we move away from the standard assumption that each income group faces the same price increases for any particular category of goods at each point in time. Let's first consider a price index allowing both the set of goods consumed and the expenditure shares to be income specific as follows:

$$
\pi_{t}^{I, \text { common }}=\prod_{j \in \Omega_{t}^{\mathrm{I}}}\left(\frac{p_{j, t}}{p_{j, 0}}\right)^{w_{j, t}^{I}}
$$

where $\pi_{t}^{I, \text { common }}$ denotes the Sato-Vartia index using common prices for income group $I$ and $\Omega_{t}^{I}$ denotes the set of goods consumed by this group at time $t$.

Figure 1 shows the price indices for different quartiles of the income distribution when we allow the expenditures shares to be group specific. The figure 
shows that the price indices track each other very closely and open very slightly during the Great Recession. Notice that the price index of the highest quartile is below that of the lowest quartile of the income distribution. This could happen, for example, if the price of the goods of which richer households consume more increased less rapidly. The graph thus shows differences in the rate of change of prices across income groups.

Next, we consider allowing prices paid to be income group specific as follows,

$$
\pi_{t}^{I, \text { effective }}=\prod_{j \in \Omega_{t}^{I}}\left(\frac{p_{j, t}^{I}}{p_{j, 0}^{I}}\right)^{w_{j, t}^{I}}
$$

where we $\pi_{t}^{I, e f f e c t i v e}$ is the cost of living inflation rate of income group $I$ calculated using the effective price $p_{j, t}^{I}$. Figure 2 illustrates how the difference between the higher quartiles and the lower quartiles grows dramatically during the Great Recession. ${ }^{15}$ In fact, over our sample period, the average annual cost of living inflation of the highest quartile was 2.0 while that of the lowest quartile was 2.7 percent and this gap mainly appeared during the Great Recession. ${ }^{16}$

It is important to mention that, in order to reduce the number of missing values when calculating our price indices, we make two important choices. First, we aggregate our index to the quarterly level. And, second, using the unit price, we calculate the indices at a higher level of aggregation (module) than the UPC level. Calculating our price indices at the UPC level requires observing at least one household from each specific income group purchasing the same UPC every time period. Keeping a balanced panel of UPCs implies losing a lot of information. This is particularly relevant in our context since we are interested in

\footnotetext{
${ }^{15} \mathrm{~A}$ possible concern is that, given that we are calculating the weighted average of the unit prices to obtain $p_{j, t}$, the variation of our indices could come only from quantities and not from changes in the effective prices. We have performed the same calculations using equal weights to generate $p_{j, t}$ and our results are very similar.

${ }^{16}$ In Figure 12 and Figure 13 we show the same calculations using a Laspeyres index. The figures show that not allowing for substitution in the calculations makes the difference between the price indices of different quartiles of the income distribution much more prominent.
} 
Figure 2: Sato-Vartia Price Index with Income Specific Prices and Expenditure Weights

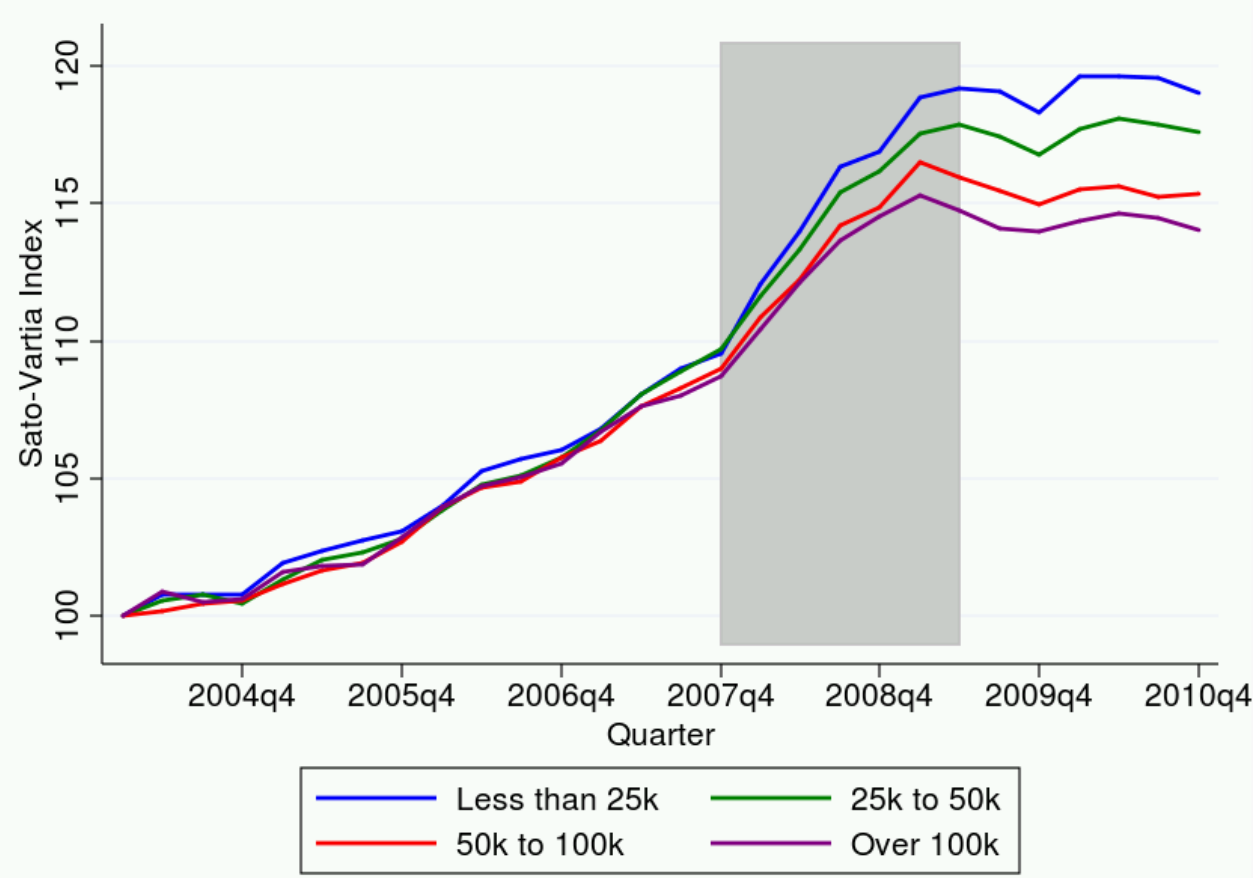

Note: The graph plots the Sato-Vartia index, from the first quarter of 2004 to the last of 2010, for each quartile of the income distribution. The expenditure weights and the prices are income specific. The indices are calculated at the quarterly frequency and at the product module level. The shaded areas indicate periods designated as recessions by the National Bureau of Economic Research. The source is the Nielsen Homescan.

studying the changes in cost of living inflation due to adjustments in the shopping behavior of households; this includes substituting products within and between categories. For this reason, we believe that, rather than assuming that the price of a UPC remains fixed until a new observation appears, aggregating at a higher level is more appropriate. Nonetheless, Figure 10 in the Appendix shows that, when we calculate the indices at the UPC level keeping a balanced panel, our results persist. Finally, in order to relax the assumption of keeping a balanced panel of observations, we construct a chained Sato-Vartia price index at the UPC level. To construct this index, we only need to observe the same set of UPC from one quarter to the next. Figure 11 in the Appendix shows that the results are qualitatively the same. 
The difference between the price indices of richer and poorer households suggests that the former was more successful at adjusting their shopping activity to reduce their effective prices. This intuition is consistent with the findings of Nevo and Wong (2014) who document that, before the recession, the highest income group had the lowest share of items purchased on sale and by 2010 it had the highest share among all other groups. Similarly, it is consistent with the work of Coibion et al. (forthcoming) who find that the degree of store switching is increasing in the household's income quintile during economic downturns.

The price indices of this section are, however, only indicative of what could be happening during the Great Recession. The main disadvantage of this approach is that it does not allow us to control for certain household characteristics that could be more prominent in certain income groups. Similarly, people of different income groups are concentrated in different geographic regions and our indices do not take that into account. Finally, this approach does not allow us to rule out the possibility that the differences in the cost of living inflation do not arise from the pricing behavior of firms and/or retailers rather than from changes in the household behavior. It could be the case, for example, that particular firms or stores, where rich people purchase, lowered their prices more. For this reason, in the next section, we approximate the price indices in a regression and explore different shopping activities separately controlling for different household and geographic observables as well as firm characteristics. Our findings suggest that it is indeed differences in shopping behavior what explains the gap in the cost of living inflation rates.

\section{Reduced Form Evidence on Shopping Behavior}

To assess whether it is easier for high-income households to devote additional resources to shopping during bad times we approximate the indices of the previous section in a regression. For simplicity, in this section we will focus in comparing only the behavior of the highest quartile of the income distribution ver- 
sus that of the lowest quartile. Our empirical specification is the following:

$$
\log P_{i, j, m, t}^{h}=\lambda+\delta_{t}+\delta_{t} \times D^{h}+\beta_{j}+\alpha_{h}+\gamma_{m}+\epsilon_{i, j, m, t}^{h}
$$

where $P_{i, j, m, t}^{h}$ is the unit value paid by household $h$, for product $i$, module $j$, in market $m$, at time $t$. $\delta_{t}$ denotes time fixed effects and $D^{h}$ is an indicator that equals one if household $h$ belongs to the highest quartile of the income distribution. Finally, $\beta_{j}$ denotes the product module fixed effects, $\alpha_{h}$ denotes the demographic controls and $\gamma_{m}$ is the county level fixed effects. In this context, $\delta_{t}$ represents price index of the lowest quartile after controlling for demographics, product categories and regions and $\delta_{t} \times D^{h}$ represents the difference in price index across income groups. Figure 3 plots the time fixed effects or the mean percent deviations from the price of the base period, in this case the first quarter of 2004, for the reference group. As shown, the constructed index mirrors those constructed in the previous section.

Panel A in Figure 4 plots the interaction term. Notice that if the price indices of the two income groups were the same the line in the graph would be completely flat. Instead, the line starts flats and starts decreasing at the beginning of the Great Recession. In this setup we can study the mechanisms households use to increase their shopping effort during bad times and whether they use them differently. We explore three possible mechanisms: shopping intensity, store switching, and quality substitution. Shopping intensity includes buying in bulk, taking advantage of sales and coupons, buying more generic products, or increasing the number of trips households make to the stores. Store switching refers to the reallocation of expenditure across stores and quality substitution to the reallocation of expenditures from high to low quality items.

We first control for shopping intensity by including controls for the mean units purchased per module in a given time period (buying bulk), the fraction of items purchased on sales, the fraction of items purchased with coupons, the fraction of expenditures in generic brands, and the number of shopping trips a 
Figure 3: Time Fixed Effects - Price Index of the Lowest Quartile

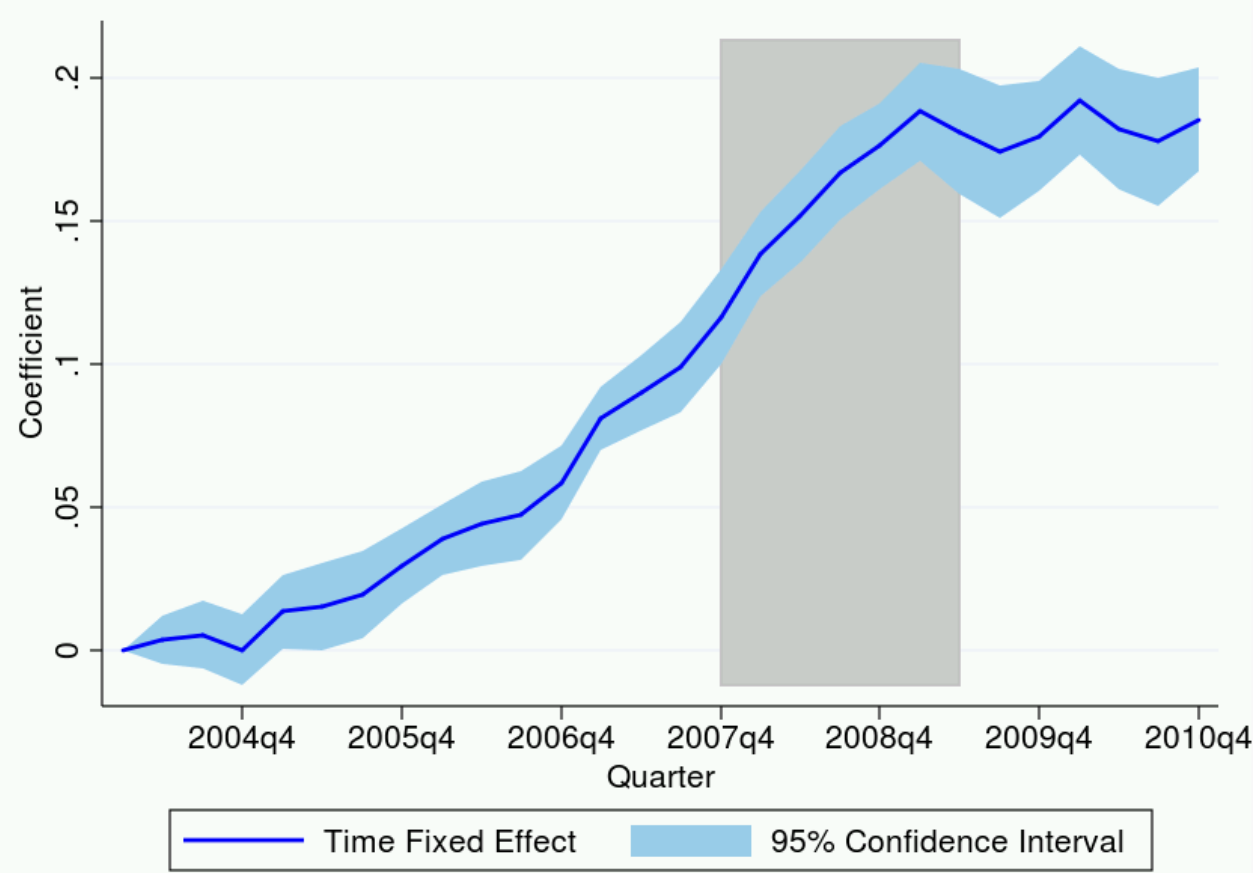

Note: The graph plots the coefficients of the time fixed effects in equation (6). The units of the y-axis are the mean percent deviations from the price of the base period (2004q1) for the lowest quartile of the income distribution. The standard errors are clustered at the product module level. The blue area indicates the $95 \%$ confidence interval. The shaded areas indicate periods designated as recessions by the National Bureau of Economic Research. The source is the Nielsen Homescan.

household makes in a given quarter. ${ }^{17}$

As depicted in Panel B, the difference between the highest and the lowest income quartiles barely reduces suggesting that differences in shopping intensity does not explain the differences we see in the price indices. This is not to say that households are not increasing their shopping intensity during the recession, in fact they do. But we are interested in what drives the differences we see in the cost of living inflation they face.

Next, we control for the reallocation of expenditures across retailers by introducing store fixed effects. Panel $\mathrm{C}$ shows that the difference in price indices reduces slightly but the standard errors widen suggesting that this is not they

\footnotetext{
${ }^{17}$ Table 7 in the Appendix present several descriptive statistics of these variables.
} 


\section{Figure 4: Difference between the Price Index of the Highest vs. the Lowest Quar- tile after Controlling for their Shopping Behavior}
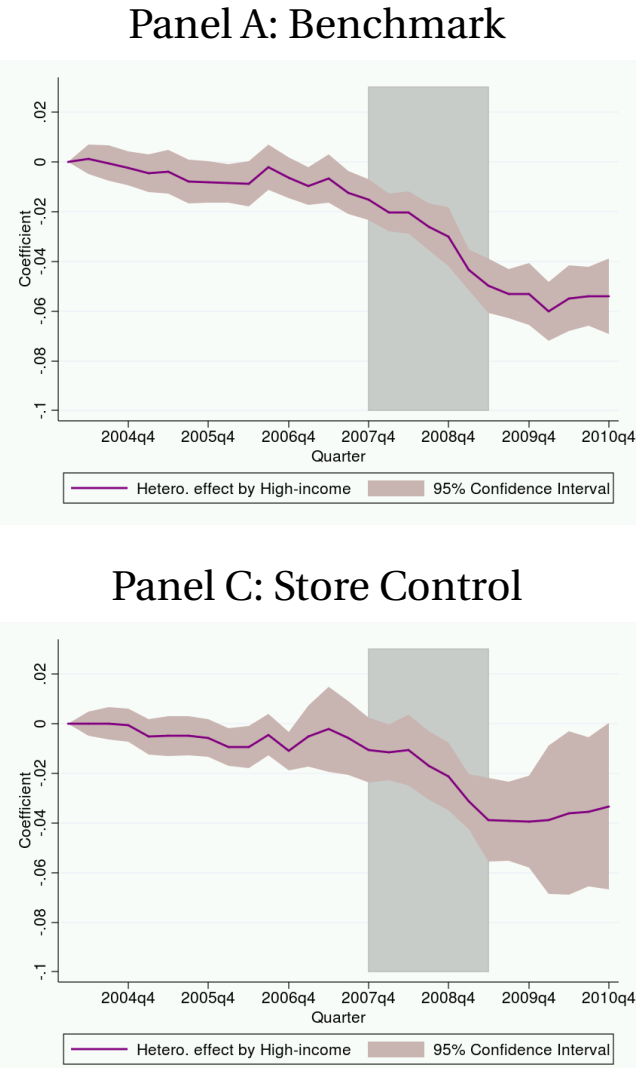

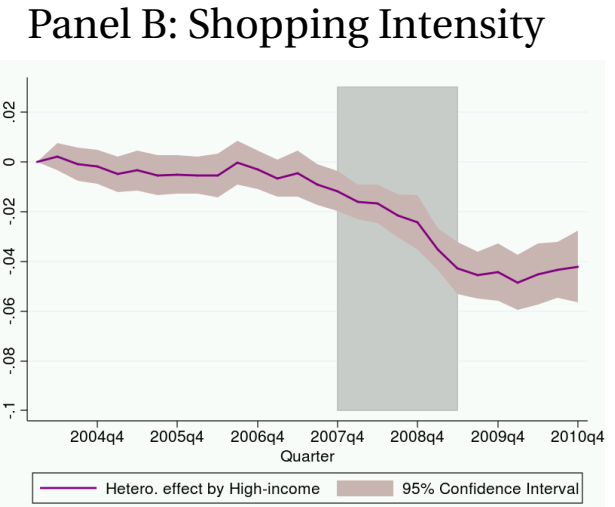

Panel D: UPC Control

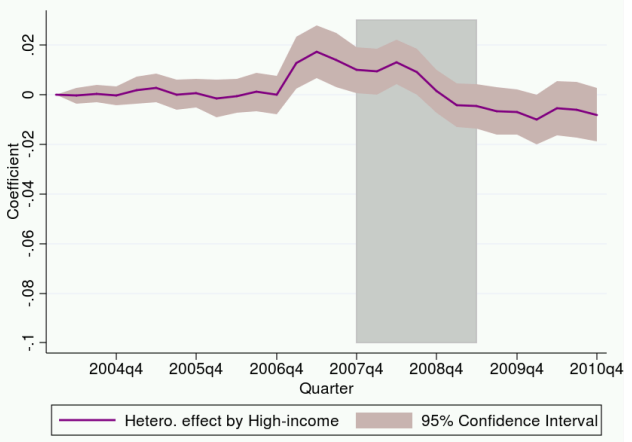

Note: The graph plots the coefficients of the interaction term in equation (6). The y-axis indicate the mean percent deviations of the prices paid by the highest quartile with respect to the lowest quartile of the income distribution. Panel A is our benchmark specification shown in equation (6). Panel B reports the results after controlling for shopping intensity: fraction of goods bought on sale, fraction of goods bought with coupons, share of expenditures on generics, number of trips in a given quarter, and mean number of units purchased in a given quarter and product module. Panel $\mathrm{C}$ depicts the results after controlling for shopping intensity and after introducing store fixed effects. Finally, Panel D reports the results obtained after introducing UPC fixed effects and shopping intensity controls. The standard errors are clustered at the product module level. The pink area indicates the $95 \%$ confidence interval. The shaded areas indicate periods designated as recessions by the National Bureau of Economic Research. The source is the Nielsen Homescan. 
main mechanism behind the gap in the price indices. In the regression depicted in the figure we also include the controls for shopping intensity.

Finally, to control for quality substitution we include UPC fixed effect in the regression. Again, we include the shopping intensity controls but leave out the store fixed effects to be able to distinguish between the two mechanisms. Panel D shows that at the end of the recession, when we control for quality substitution, the difference between the cost of living inflation rates faced by the highest and lowest income quartiles vanishes. These results suggest that the ability to substitute from higher to lower quality brands is increasing in household income during economic downturns and that it provides an additional margin of adjustment to richer households.

\section{Pricing Behaviors of Retailers and Firms}

The differences in the cost of living inflation that we observe could also arise from the pricing behavior of retailers rather than from the adjustment of consumer behavior during the recession. In order to rule out this possibility we use the store level data of prices, collected by IRI Symphony, to construct two measures of inflation: posted and effective. Posted prices refer to the prices posted by retailers and effective prices refer to the prices paid by consumers. In order to compare the cyclical sensitivity of inflation in posted and effective prices, we conduct the same exercise as Coibion et al. (forthcoming) before and after the recession period (i.e. 2006 to 2010). Our interest is to determine whether inflation in posted or effective prices has a higher impact in determining the cost of living inequality that we observe.

To construct the posted price inflation, we first calculate the average retail price in a given week:

$$
P_{m s c t j}=\frac{T R_{m s c t j}}{T Q_{m s c t j}}
$$


where $m, s, c, t$, and $j$ index market (Metropolitan Statistical Area), store, product category (i.e. milk), time (i.e. month), and UPC respectively. We then compute the UPC specific monthly posted price inflation rates as $\log \left(\frac{P_{m s c j t}}{P_{m s c j, t-1}}\right)$ and aggregate across all goods and stores using three weighting schemes: i) equal weights; ii) expeditures shares for each market and year (market-specific); iii) cross-market expenditures shares for each year (common). Finally, we cumulate monthly inflation rates into annual inflation rates $\bar{\pi}_{m c t}^{\text {post }}$.

Our measure of effective price inflation focuses on substitution across goods. Since the dataset includes detailed information about the volume of each UPC, we can construct the quantity-weighted average price paid by consumers in quantity-equivalent measures (unit value) as follows:

$$
\bar{P}_{m c t s}^{e q}=\frac{\sum_{j \in c} T R_{m s c t j}}{\sum_{j \in c} T Q_{m s c t j} \times E Q_{j}}
$$

where $E Q_{J}$ is the quantity equivalent of good $j$. We then compute the montly inflation rate $\log \left(\frac{\bar{P}_{\text {encst }}^{e q}}{\left.\bar{P}_{m c s, t-1}^{q}\right)}\right)$ and aggregate across all stores in each market to get the average product category inflation rate using either equal, market specific or common weights. Finally, we cumulate monthly inflation rates into annual inflation rate $\bar{\pi}_{m c t}^{e q}$. Notice that, in this case, the store weights are fixed which allows us to focus on the consumer substitution of goods within a product category. The sensitivity of these inflation rates to economic conditions is then assessed using

$$
\bar{Y}_{m c t}=\beta U R_{m t}+\lambda_{t}+\theta_{m c}+\varepsilon_{m c t}
$$

where $\bar{Y}_{m c t}$ refers to either posted or effective inflation; $U R_{m t}$ is the local seasonally adjusted unemployment rate; $\lambda_{t}$ denotes time fixed effects; $\theta_{m c}$ denotes fixed effect for each market and category. ${ }^{18}$ Our results are presented in Table 1

\footnotetext{
${ }^{18}$ Coibion et al. (forthcoming) argue that when time fixed effects are included the estimates of the regression may be interpreted as causal. This is because most goods sold in stores are not produced locally, which avoids the typical endogeneity problem associated with regressions of prices on real economic activity.
} 
and 2. Consistent with Coibion et al. (forthcoming), we find little cyclical sensitivity of posted-price inflation measures to local unemployment rate under the three weighting schemes (shown in columns 1, 5 and 9). One percentage point increase in the local unemployment rate decreases inflation in posted prices by 0.03-0.05 percentage points.

Since local unemployment rates may reflect a combination of local supply and demand factors (Stroebel and Vavra, 2014), we conduct the same analysis focusing on exogenous changes in house prices. We follow the recent literature that exploits MSA level variation in housing supply elasticity, a measure developed by Saiz (2010), as an instrument for changes in house prices. ${ }^{19}$ Since the instruments vary only in the cross-section, we instrument housing price growth rates with the product of the housing supply elasticity and the nationwide housing price growth rate, measured by the U.S. purchase only house price index. ${ }^{20}$ The idea of this instrument is that, for a given housing demand shock, house prices should rise more in cities where housing is less elastically supplied. The first and second stages of the IV regression are given by equations 8 and 9 , respectively

$\Delta \log (\text { HousePrice })_{m, t}=\rho$ SupplyElasticity ${ }_{m} \times \Delta \log (\text { HousePrice })_{t}+\lambda_{t}+\theta_{m}+\epsilon_{m, t}$

$$
\bar{Y}_{m c t}=\beta \Delta \log (\text { HousePrice })_{m, t}+\lambda_{t}+\theta_{m}+\epsilon_{m, t}
$$

where $\bar{Y}_{m c t}$ refers to either posted or effective inflation; $\lambda_{t}$ denotes time (i.e. month) fixed effects; $\theta_{m c}$ denotes the MSA fixed effect. We obtain house price indices at the MSA level from Zillow. We use Zillow Home Value Index (ZHVI) for all homes which is the median estimated home value for all homes (single

\footnotetext{
${ }^{19}$ See, for example, Mian and Sufi (2011, 2014); Adelino et al. (2013); Bhutta and Keys (2014).

${ }^{20}$ Stroebel and Vavra (2014) suggested this strategy, following Bartik (1991)'s intuition. The exclusion restriction requires that changes in the national housing prices interacted with local supply elasticity affect posted and effective prices only through their effect on local housing price growth.
} 
family residence, condo and co-op) within a region. Our final sample contains 43 metropolitan areas across the U.S.

Our results are presented in Table 1 and 2. Both for posted and effective prices, OLS estimates (columns 2, 6, 10) are underestimated compared to IV estimates (columns $3,7,11$ ). This is consistent with omitted variable bias: the presence of local productivity shocks would lower inflation but raise house price. We find a significant positive response of posted inflation to changes in house prices. Our results capture the causal effect of house price growth on inflation even after controlling for the local unemployment rate (columns 4, 8, 12). Our results for posted prices are consistent with the findings of Stroebel and Vavra (2014) who conducts a similar analysis and documents a causal positive response of local retail prices levels to changes in house prices. The response of inflation in effective prices is, nonetheless, significantly larger. The coefficients for inflation in effective prices are 2-5 times larger than those obtained for inflation in posted prices. This finding suggests, not only that effective prices are significantly more sensitive to local demand shocks, but also that the cost of living inequality that we observe among consumers are more likely to be driven by product substitution rather than the pricing behavior of retailers. 
Table 1: Posted Inflation and Local Demand Shocks

\begin{tabular}{|c|c|c|c|c|c|c|c|c|c|c|c|c|}
\hline & \multicolumn{4}{|c|}{ Equal } & \multicolumn{4}{|c|}{ Market-specific } & \multicolumn{4}{|c|}{ Common } \\
\hline & (1) & $(2)$ & (3) & $(4)$ & (5) & (6) & (7) & (8) & (9) & $(10)$ & (11) & (12) \\
\hline & & OLS & IV & IV & & OLS & IV & IV & & OLS & IV & IV \\
\hline \multirow[t]{2}{*}{ Unemployment Rate } & $-0.050^{* *}$ & & & $-0.048^{* *}$ & -0.038 & & & -0.034 & -0.033 & & & -0.028 \\
\hline & $(0.019)$ & & & $(0.019)$ & $(0.031)$ & & & $(0.030)$ & $(0.033)$ & & & $(0.032)$ \\
\hline \multirow[t]{2}{*}{ House Price Growth } & & $0.068^{* *}$ & $0.299^{* *}$ & $0.280^{* *}$ & & $0.138^{* * *}$ & $0.518^{* *}$ & $0.505^{* *}$ & & $0.152^{* * *}$ & $0.547^{* *}$ & $0.536^{* *}$ \\
\hline & & $(0.031)$ & $(0.139)$ & $(0.139)$ & & $(0.044)$ & $(0.230)$ & $(0.226)$ & & $(0.048)$ & $(0.251)$ & $(0.247)$ \\
\hline
\end{tabular}

Notes: We use market $\times$ category fixed effects and month fixed effects. Number of observations are 75,481 . Driscoll and Kraay (1998) standard errors are in parenthesis. ${ }^{* * *},{ }^{* *},{ }^{*}$ denote significance at $0.01,0.05$, and 0.10 levels.

Table 2: Effective Inflation and Local Demand Shocks

\begin{tabular}{|c|c|c|c|c|c|c|c|c|c|c|c|c|}
\hline & \multicolumn{4}{|c|}{ Equal } & \multicolumn{4}{|c|}{ Market-specific } & \multicolumn{4}{|c|}{ Common } \\
\hline & $(1)$ & $(2)$ & (3) & (4) & (5) & (6) & $(7)$ & (8) & (9) & $(10)$ & $(11)$ & (12) \\
\hline & & OLS & IV & IV & & OLS & IV & IV & & OLS & IV & IV \\
\hline \multirow[t]{2}{*}{ Unemployment Rate } & $-0.111^{* * *}$ & & & $-0.105^{* * *}$ & $-0.114^{* * *}$ & & & $-0.107^{* * *}$ & $-0.114^{* * *}$ & & & $-0.107^{* * *}$ \\
\hline & $(0.027)$ & & & $(0.027)$ & $(0.029)$ & & & $(0.029)$ & $(0.029)$ & & & $(0.030)$ \\
\hline \multirow[t]{2}{*}{ House Price Growth } & & $0.158^{* *}$ & $0.631^{* *}$ & $0.589^{* *}$ & & $0.251^{* * *}$ & $0.824^{* * *}$ & $0.781^{* * *}$ & & $0.262^{* * *}$ & $0.835^{* * *}$ & $0.792^{* * *}$ \\
\hline & & $(0.061)$ & $(0.253)$ & $(0.255)$ & & $(0.071)$ & $(0.262)$ & $(0.261)$ & & $(0.073)$ & $(0.267)$ & $(0.266)$ \\
\hline
\end{tabular}

Notes: We use market $\times$ category fixed effects and month fixed effects. Number of observations are 69,819. Driscoll and Kraay (1998) standard errors are in parenthesis. ${ }^{* *},{ }^{* *},{ }^{*}$ denote significance at $0.01,0.05$, and 0.10 levels. 
An alternative explanation could be retailers' second degree price discrimination motive which induces them to charge different prices to different consumers. This could be the case if they try, for instance, to minimize the possibility of consumers switching to less-preferred goods to save money. Chevalier and Kashyap (2011) argue, for example, that retailers might employ strategies to charge different prices to "active" consumers, who are more likely to substitute across products in a narrowly defined categories, and "passive" consumers. ${ }^{21}$ If the retailers forecast that high income consumers are more likely to switch brands, given that they are more likely to purchase high-priced products, they might lower the prices of more expensive products to limit the degree of switching among rich consumers. If this is the case, our results could be driven by price discrimination rather than consumers substituting across brands to smooth their consumption. In order to explore this hypothesis we divide the products in two types, high-priced and low-priced, following the procedure developed by Chevalier and Kashyap (2011). We calculate the total amount spent in each week and store divided by the total volume sold in that week. We call this the benchmark price per volume for that store in that week. We define highpriced products as those products that are on average $25 \%$ above the benchmark price and low-priced products as those that are on average below $25 \%$ of the benchmark price. We then compute posted price inflation for each type. By comparing the inflation in posted prices of high-priced products with respect to low-priced products we can approximate the degree in which retailers charge differential prices to customers during the recession. We use the following specification

$$
\bar{Y}_{m c q t}=\beta_{1} \text { DemandShock }_{m t}+\beta_{2} \text { DemandShock }_{m t} \times D_{m c t}^{H}+\lambda_{t}+\theta_{m c q}+\varepsilon_{m c t}
$$

\footnotetext{
${ }^{21}$ In their model, the seller optimally sets prices to encourage deal-driven brand switching only by those consumers who have the least disutility from switching brands. Their empirical results suggest that many consumers have a low disutility of switching brands.
} 
Table 3: Posted Inflation and Local Demand Shocks by Product Type

\begin{tabular}{l|cc|cc|cc} 
& \multicolumn{2}{|c|}{ Equal } & \multicolumn{2}{c|}{ Market-specific } & \multicolumn{2}{c}{ Common } \\
& $(1)$ & $(2)$ & $(3)$ & $(4)$ & $(5)$ & $(6)$ \\
\hline House Price Growth & 0.041 & $0.077^{* *}$ & $0.117^{* *}$ & $0.114^{* * *}$ & $0.132^{* *}$ & $0.134^{* * *}$ \\
House Price Growth $\times$ High Priced & $(0.044)$ & $(0.030)$ & $(0.057)$ & $(0.038)$ & $(0.062)$ & $(0.040)$ \\
Unemployment Rate & 0.067 & & -0.006 & & 0.003 & \\
& $(0.056)$ & & $(0.067)$ & & $(0.078)$ & \\
Unemployment Rate $\times$ High Priced & $-0.049^{*}$ & $-0.059^{*}$ & $-0.079^{* *}$ & $-0.100^{*}$ & $-0.075^{*}$ & $-0.100^{*}$ \\
& $(0.026)$ & $(0.034)$ & $(0.038)$ & $(0.052)$ & $(0.040)$ & $(0.058)$ \\
& & 0.019 & & 0.041 & & 0.048 \\
& & $(0.019)$ & & $(0.029)$ & & $(0.034)$
\end{tabular}

Notes: We use market $\times$ category $\times$ quality-type fixed effects and month fixed effects. Number of observations are 144,376. Driscoll and Kraay (1998) standard errors are in parenthesis. ${ }^{* * *},{ }^{* *},{ }^{*}$ denote significance at $0.01,0.05$, and 0.10 levels.

where $\bar{Y}_{m c q t}$ refers to either posted or effective inflation of products in market $m$, category $c$, type $q$ (i.e. high-priced and low-priced), and time period $t$; DemandShock ${ }_{m t}$ is either the local unemployment rate or the local house prices; $D_{m c t}^{H}$ is a dummy variable equal one if the products in category $c$ and market $m$ is high-priced. The results are presented in Table 3. We do not find significant interaction effects with type of product: high-priced products do not experience larger price decreases than low-priced products. For both demand shocks (i.e. unemployment rate and house prices) and the three weighting schemes (i.e. equal, market specific, and common) the coefficients do not indicate that retailers or firms lower the prices of more expensive products more to limit the degree of brand switching of rich consumers.

Finally, one might be concerned that price setters are not the retailers but the firms and a supply shock to the firms during the recession may have affected consumers differently. Gilchrist et al. (2013), for example, using con- 
fidential producer price data, show that during the crisis firms with relatively weak balance sheets increased prices while firms with strong balance sheets lowered prices. If firms with strong balance sheets are mainly selling to high income consumers, our results could be driven by changes in firms' price-setting behavior. In order to explore whether this is the case, we first identify the manufacturer of each UPC-level product using the first six to nine digits of the barcode. Then, in order to link the manufacturer to the firm producing the product, we merge the Homescan dataset to the GS1 dataset, the single official source of barcodes in the US. ${ }^{22}$ Table 8 in the Appendix shows the share of expenditures by firm. The table shows that only the top 15 firms account for more than $60 \%$ of the total expenditures in the Homescan data. This also holds if we consider the expenditure shares of each income group separately. This shows that most of the purchases of consumers come from the same set of firms. In the table, we also see that the share of expenditures of each income group in each of the firms is very similar. For example, the share of expenditures in Nestle products by the highest and lowest income quartiles are $8.36 \%$ and $8.29 \%$ respectively. ${ }^{23}$ Importantly, this pattern is very similar for the rest of the approximately 450 firms that we are able to identify, showing that there is not a clear match between firms of certain characteristics and income groups.

\section{Direct Evidence on Shopping Behavior}

The key message of the previous sections is that the cost of living inequality that we document could be explained by the way consumers adjust their shopping behavior. In this section, we provide evidence that the changes in the shopping

\footnotetext{
${ }^{22}$ The Homescan dataset includes under 5 percent of barcodes not issued in the US. We were not able to find a firm identifier for these products so we dropped them in this part of the analysis.

${ }^{23}$ The one exception is Wal-Mart Stores Inc which sells generic items. In this case, the share of expenditures by the richer groups is lower than that of the poorer groups. This is mainly due to the fact that the share of expenditures of richer households in Wal-Mart is significantly lower than that of the other groups.
} 
behavior of households are not specific to the Great Recession and occur also when households face idiosyncratic income shocks.

We use the Nielsen Retail Scanner data to obtain the universe of products sold by the retailers in our sample. This dataset allows us to calculate the average relative prices of products and stores to approximate their quality. In this case, a product or store with higher relative prices is considered to be higher in the quality ladder. Then, we combine this information with the Nielsen Homescan to construct household-specific average product and store quality in a given period of time. Finally, exploiting the panel structure of our data, we can study whether households adjust their shopping behavior after facing an income drop. Our combined dataset covers from 2006 to 2010. Given the massive size of the Retail Scanner dataset, we choose to focus on Chicago metropolitan area. ${ }^{24}$ Our calculations for the average relative prices use more than 2.6 billion transactions in the Chicago area and our final dataset consists of 3,336 households and 1,962 stores. ${ }^{25}$

\subsection{Definition of Shopping Behavior Variables}

As before, in this section, we focus on three major ways consumers can save when they suffer income shocks: increasing shopping intensity, switching to low quality stores, and substituting down to lower quality products within a category.

Shopping Intensity: To approximate shopping intensity, in this section, we use the number of shopping trips and the fraction of items purchased on sale. ${ }^{26}$

\footnotetext{
${ }^{24}$ The magnitude of the recession in the Chicago metropolitan area, as measured by its average unemployment rate, is close to the national average during the recession (see Figure 14).

${ }^{25}$ The Chicago scantrack market in the Homescan includes 6 counties in Illinois (Cook, DuPage, Kane, Lake, McHenry, and Will) and 2 counties in Indiana (Lake and Porter).

${ }^{26}$ For the sake of brevity, in this section we only show the results of the fraction of items purchased on sale. We have performed the same analysis with coupon usage, purchases of generic products, and buying in bulk finding similar results. This is consistent with the results by Petev et al. (2011), who argue that these activities have similar business-cycle patterns.
} 
As before, a shopping trip is defined by the date and store of the transaction (Aguiar and Hurst (2007)). That is, transactions at two stores on the same day are counted as two trips. Similarly, two transactions at the same store on two different days are counted as two trips. By making more shopping trips, households could exploit store and manufacturer discounts more frequently. ${ }^{27}$ In addition, in the Homescan data, a transaction is defined as being on sale if the household recorded that the item purchased involved a deal. We measure the fraction of items purchased on sale by a given household in a given quarter.

Store Switching To assess the reallocation of expenditures across stores, we first construct stores' quarterly relative prices as Coibion et al. (forthcoming) suggest. First, for each UPC-level good $j$ in store $s$ and county $m$, we calculate the log-difference between the price of good $j$ in store $s$ and the median price for good $j$ across all stores in a given county and quarter. ${ }^{28}$

$$
R_{j s t}=\log \frac{P_{j s t}}{\bar{P}_{j t}}
$$

where $R_{j s t}$ is the relative price and $\bar{P}_{j t}$ is the median price.

We then compute the average relative price for a store across the set of UPC products $\Omega$. We consider several versions of $\Omega$ since different retailers sell different UPCs: i) $\Omega_{\max }$ includes all UPCs sold in every store; ii) $\Omega_{90}$ only includes UPCs sold in at least $90 \%$ of stores; iii) $\Omega_{75}$ only includes UPCs sold in at least $75 \%$ of stores. The average relative price (quality) of a store for a given $\Omega$ is

$$
Q_{s t}^{\text {store }}=\sum_{j \in \Omega} \omega_{j s t} R_{j s t}
$$

\footnotetext{
${ }^{27}$ Homescan data does not record the length of each shopping trip, just the number of transactions. Aguiar and Hurst (2007) supplements the Homescan data using the American Time Use Survey (ATUS). Since the time spent at shopping in ATUS has remained relatively stable over our sample period (Petev et al. (2011)), in this section we only focus on the number of shopping trips.

${ }^{28}$ To simplify notation, we drop the subscript $m$ used to denote a particular county
} 
where $\omega_{j s t}$ is a revenue weight. $Q_{s t}^{\text {store }}$ captures how far a store's average price level is from the median price level in a quarter.

Now, we can construct an average relative price (quality) of stores at which household $h$ shopped in quarter $t$ as follows:

$$
Q_{h t}^{\text {store }}=\sum_{s} \psi_{h s t} Q_{s t}^{\text {store }}
$$

where $\psi_{h s t}$ is an expenditure weight. Finally, $Q_{h t}^{\text {store }}$ represents the average quality of store where individual households $h$ consume. Given this measure, we can assess the store-switching phenomenon at the level of individual households.

Product Quality Substitution Similar to the average relative price (quality) of store, we construct the average relative price (quality) of UPC-level good within category. First, we measure the log-difference between the price of good $j$ in store $s$ and the median price for category $c$ in store $s$.

$$
R_{j s t}=\log \frac{P_{j s t}}{\bar{P}_{c s t}}
$$

where $R_{j s t}$ is the relative price and $\bar{P}_{c s t}$ is the median price of category $c$ in store s. $R_{j s t}$ is large and positive, for example, if the price of a high quality type of milk, say organic milk, is much larger than the median price of milk in that store. We then compute the average relative price for UPC-level goods across the set of stores $\Omega$. We consider several versions of $\Omega$ as before: i) $\Omega_{\max }$ includes all stores selling every product; ii) $\Omega_{90}$ only includes stores selling at least $90 \%$ of UPCs; iii) $\Omega_{75}$ only includes stores selling at least $75 \%$ of UPCs. The average relative price (quality) of a good for a given $\Omega$ is

$$
Q_{j t}^{\text {product }}=\sum_{s \in \Omega} \omega_{j s t} R_{j s t}
$$

where $\omega_{j s t}$ is a revenue weight. $Q_{j t}^{\text {product }}$ captures how far a product's average price level is from the median price level of category in a quarter. In order to 
aggregate across various categories, we standardize the relative price distribution dividing by the standard deviation. ${ }^{29}$ Note that the median is already zero by construction. ${ }^{30}$

Now, we construct an average relative price (quality) of products household $h$ bought in quarter $t$ as follows:

$$
Q_{h t}^{\text {product }}=\sum_{j} \psi_{h j t} Q_{j t}^{\text {product }}
$$

where $\psi_{h s t}$ is an expenditure weight. A low (high) value of $Q_{h t}^{\text {product }}$ implies that household $h$ bought low (high) quality products in quarter $t$.

Having obtained measures of the quality of items households purchase, we can now plot the distribution of product quality for each income quartile. Figure 5 shows the distribution of product quality for households belonging to the lowest and highest quartiles of the income distribution. The solid lines show the distribution of quality before 2008 and the dashed lines the distribution of product quality after 2008 for Will County, one of the largest counties in the Chicago metropolitan area. ${ }^{31}$ The distribution of product quality for the highest quartile suffered a large shift to the left after the recession, indicating large product quality substitution among richer households. On the other hand, the distribution of product quality for poorer households remains stable as the majority of the products purchased by this income group were already significantly below the median price for each category. The figure illustrates well the mechanism described in the previous sections. The fact that poor households were already purchasing items ranked low in the product quality distribution hindered their ability to substitute to products ranked even lower. Rich households, on the

\footnotetext{
${ }^{29}$ We do this to minimize the variation of the relative price distribution of the more than 1,000 product categories that we have in our data.

${ }^{30}$ Even after this normalization, the relative price distribution has high kurtosis. For $\Omega_{\max }$ case, kurtosis decreases from 12.84 to 10.16. This leptokurtic price distribution is consistent with Kaplan and Menzio (2014).

${ }^{31}$ According to the 2010 Census, Will County had a total population of 677,560 and is the fourth most populous county in Illinois.
} 
Figure 5: Product Quality Distribution Before and After the Recession

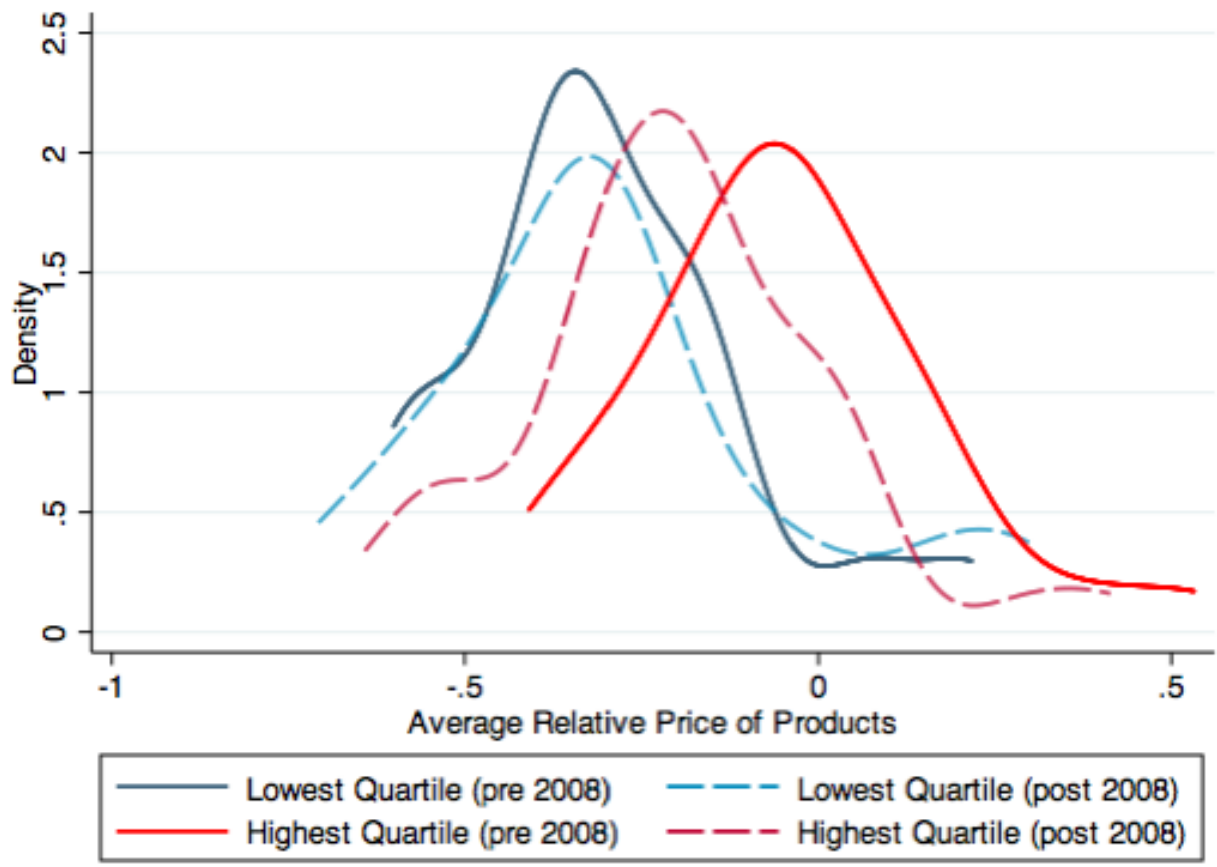

Note: The graphs shows the distribution of average relative prices paid by the highest and the lowest quartiles of the income distribution in Will County. The solid red (green) line denotes the distribution of average relative prices paid by the highest (lowest) quartile before 2008. The dashed lines denote the same distribution after 2008. The densities are estimated with a Gaussian kernel function.

other hand, used this margin effectively to mitigate the shock.

\subsection{Change in Shopping Behavior after a Negative Income Shock}

In this section, we use our household specific estimates of product and store quality along with our shopping intensity measures to assess the changes in shopping behavior after an idiosyncratic shock. Given that we observe the households annual income in the Homescan data, we can exploit this information to study how they adjust their behavior to mitigate income drops. ${ }^{32}$ Specifically,

\footnotetext{
${ }^{32}$ Panelists are asked to report their combined total household annual income as of year-end of the previous calendar year. Nielsen believes, however, that panelists are actually reporting their "annualized" estimated income as of the time of the survey and not referring to previous
} 
we use the following empirical specification:

$$
Y_{h t}=\lambda+\theta \times \text { IncomeDrop }_{h t}+\alpha_{h}+\delta_{t}+\epsilon_{h t}
$$

where $Y_{h t}$ represent the shopping behavior variables for household $h$ in quarter $t$ and IncomeDrop ${ }_{h t}$ equals one if the annual income of household $h$ falls more than twenty percent from its previous annual income. ${ }^{33} \alpha_{h}$ and $\delta_{t}$ are household and time fixed effects. Since the error term is likely to be serially and cross-sectionally correlated, we use Driscoll and Kraay (1998) standard errors. When time fixed effects are included, estimates of $\theta$ assess the strength of correlation between household specific income changes and their shopping behavior. While aggregate shocks could lead to simultaneous movements in shopping behavior and household income, controlling for time fixed effects eliminate this issue. Therefore, by exploiting only the cross-sectional variation, our aim is to show that our findings about the importance of product quality substitution to richer households are present also when households face idiosyncratic income shocks.

The results are presented in Table 4. Store quality is negatively associated with a negative income shock. Quantitatively, twenty percent income drop decreases average store quality by two percentage points. In other words, households facing lower income reallocate their expenditures to stores with lower average relative prices. This is consistent with Coibion et al. (forthcoming) who find that households reallocate their purchases toward low-price stores when economic conditions worsen. Our results arise, however, from household-level variation as opposed to regional variation. Furthermore, product quality is also negatively associated with a negative income shock by three percentage points, indicating that households facing a negative income shock reallocate their expenditures towards lower quality products within a given category.

year tax returns.

${ }^{33}$ Overall, $11.15 \%$ of households experienced a drop in income higher than twenty percent. The share of income drop has increased over time, $8.91 \%$ in $2007,10.19 \%$ in $2008,8.89 \%$ in 2009 , and $15.83 \%$ in 2010. 
Table 4: Shopping Behavior after a Negative Income Shock

\begin{tabular}{|c|c|c|c|c|c|c|c|c|}
\hline \multirow{2}{*}{$Y_{h t}$} & \multicolumn{3}{|c|}{ Store Quality } & \multicolumn{3}{|c|}{ Product Quality } & \multirow{2}{*}{ Trips } & \multirow{2}{*}{ Sales } \\
\hline & $\Omega_{\max }$ & $\Omega_{90}$ & $\Omega_{75}$ & $\Omega_{\max }$ & $\Omega_{90}$ & $\Omega_{75}$ & & \\
\hline \multirow{2}{*}{ IncomeDrop } & $-.0240^{* *}$ & -.0193 & $-.0209 * *$ & $-.0351^{*}$ & $-.0390^{* *}$ & -.0270 & .3029 & .0012 \\
\hline & $(.0107)$ & $(.0127)$ & (.0098) & $(.0186)$ & $(.0180)$ & (.0189) & $(.4075)$ & $(.0015)$ \\
\hline Fixed Effects & \multicolumn{8}{|c|}{ Yes } \\
\hline No. of Obs. & 31,275 & 31,274 & 31,274 & 31,938 & 31,904 & 31,924 & 31,987 & 31,987 \\
\hline
\end{tabular}

Note: The table reports regression coefficients for the change in shopping behavior after a negative income shock. Numbers on store quality and product quality are standardized coefficients so they can be interpreted as the number of standard deviations dependent variable changes in response to a change of a standard deviation in the independent variable. Number of trips and sales are not standardized so they can be interpreted as the number of additional shopping trips or the additional fraction of items purchased on sale after an income drop respectively. Standard errors are corrected by Driscoll and Kraay (1998).

Finally, the point estimates of the variables measuring shopping intensity are positive but not significant for the Chicago sample. Since we do not need the Retail Scanner dataset to run equation (7) for our measures of shopping intensity, we repeat the exercise with the full sample of regions in the Homescan dataset. We find that, in this case, the coefficients of the shopping intensity variables are of similar magnitude as those shown in Table 4 but this time statistically significant. Intuitively, household, on average, are likely to make more shopping trips and buy more items on sale when their income falls.

We now turn to examine which types of households are most likely to adjust their shopping behavior. We do so by using the following empirical specification:

$$
Y_{h t}=\lambda+\theta_{1} \times \text { IncomeDrop }_{h t}+\theta_{2} \times \text { IncomeDrop }_{h t} \times D_{h}+\alpha_{h}+\delta_{t}+\epsilon_{h t}
$$

where $Y_{h t}$ and IncomeDrop ${ }_{h t}$ are specified as before and $D_{h}$ is dummy variable that is one if household's income is above than the median of the household 
Table 5: Heterogeneous Shopping Behavior after a Negative Income Shock

\begin{tabular}{|c|c|c|c|c|c|c|c|c|}
\hline \multirow{2}{*}{$Y_{h t}$} & \multicolumn{3}{|c|}{ Store Quality } & \multicolumn{3}{|c|}{ Product Quality } & \multirow{2}{*}{ Trips } & \multirow{2}{*}{ Sales } \\
\hline & $\Omega_{\max }$ & $\Omega_{90}$ & $\Omega_{75}$ & $\Omega_{\max }$ & $\Omega_{90}$ & $\Omega_{75}$ & & \\
\hline \multirow{2}{*}{ IncomeDrop } & -.0149 & .0088 & -.0034 & -.0290 & -.0351 & -.0216 & $-.8946^{* *}$ & .0025 \\
\hline & $(.0188)$ & $(.0192)$ & $(.0170)$ & $(.0205)$ & $(.0242)$ & $(.0223)$ & (.4025) & $(.0023)$ \\
\hline \multirow{2}{*}{ IncomeDrop $\times D$} & -.0200 & -.0617 & -.0382 & -.0134 & -.0086 & -.0117 & $1.2977^{*}$ & -.0029 \\
\hline & $(.0353)$ & $(.0373)$ & $(.0347)$ & $(.0317)$ & $(.0395)$ & $(.0327)$ & $(.6262)$ & $(.0036)$ \\
\hline Fixed Effects & \multicolumn{8}{|c|}{ Yes } \\
\hline No. of Obs. & 31,275 & 31,274 & 31,274 & 31,938 & 31,904 & 31,924 & 31,987 & 31,987 \\
\hline
\end{tabular}

Note: The table reports regression coefficients for the change in shopping behavior after a negative income shock. Numbers on store quality and product quality are standardized coefficients so these refer to how many standard deviations a dependent variable will change. Numbers on trips and sales are not standardized so you can interpret as how much consumers will increase their number of shopping trip and share of purchase on sale after the shock. Standard errors are corrected by Driscoll and Kraay (1998).

income distribution. Thus, $\theta_{2}$ represents the heterogeneous response by high income households. The point estimates of this specification for both store and product quality, shown in Table 5, are negative but not significant. The sign of the interaction term indicates that higher income households adjust the quality of products they purchase and the stores at which they buy more with respect to households below the median of the income distribution. Although the signs obtained in this exercise are consistent with our overall argument, working with a reduced sample of households does not allow us to have enough power to reject the null hypothesis in this case. ${ }^{34}$ Nonetheless, our results suggest that, since poor households purchase a large share of their products at the bottom of the distribution of product quality, they lack the product substitution margin when they face an income drop. Richer households, on the other hand, are able

\footnotetext{
${ }^{34}$ The direction of our results are consistent with the findings of Stroebel and Vavra (2014) who also show heterogeneous responses of different consumers after wealth shocks. Using a similar approach, they find that renters are less likely to adjust their shopping behavior after changes in housing wealth than homeowners.
} 
to take advantage of this margin to mitigate income shocks.

\section{Implications}

Our results have important implications in the measurement of inflation. The presence of product-substitution indicates that the substitution bias, arising from using a fixed basket to compute price indices when people substitute away from expensive items, is higher during recessions. This suggests that statistical agencies should attempt to track effective rather than posted prices particularly during bad times. Although we acknowledge that this may impose a large burden on them, alternative methodologies to do it, such as the one proposed by Chevalier and Kashyap (2011), could be a good starting point. In addition, our paper suggests that, given the large differences in the cost of living inflation across income groups, these agencies should explore alternatives to produce income-specific price indices.

Our results also affect the interpretation of studies that estimate both consumption and income inequality. In recent years, a large literature has compared the trend of consumption inequality to that of income inequality. ${ }^{35}$ During the Great Recession, unemployment quickly rose, asset prices fell, and many households suffered large changes in wealth. Thus, accurately measuring the patterns of income and consumption before and after the recession is particularly important.

Meyer and Sullivan (2013) use data from the Current Population Survey (CPS) and the Consumer Expenditure Survey (CE) to document that, between 2008 and 2011, income inequality rose sharply while consumption inequality fell drastically. Using the Nielsen Homescan data we conduct a similar exercise and compute the total annual expenditures by income quartile. We then compute

\footnotetext{
${ }^{35}$ The literature is still divided between studies that have found that the rise in both have been similar (Aguiar and Bils, 2011; Attanasio et al., 2014), while other studies have argued that consumption inequality has risen less than income inequality in recent decades (Cutler et al., 1991; Krueger and Perri, 2006; Heathcote et al., 2010; Fisher et al., 2014; Meyer and Sullivan, 2013).
} 
Figure 6: Highest to Lowest Quartile Expenditure Ratio

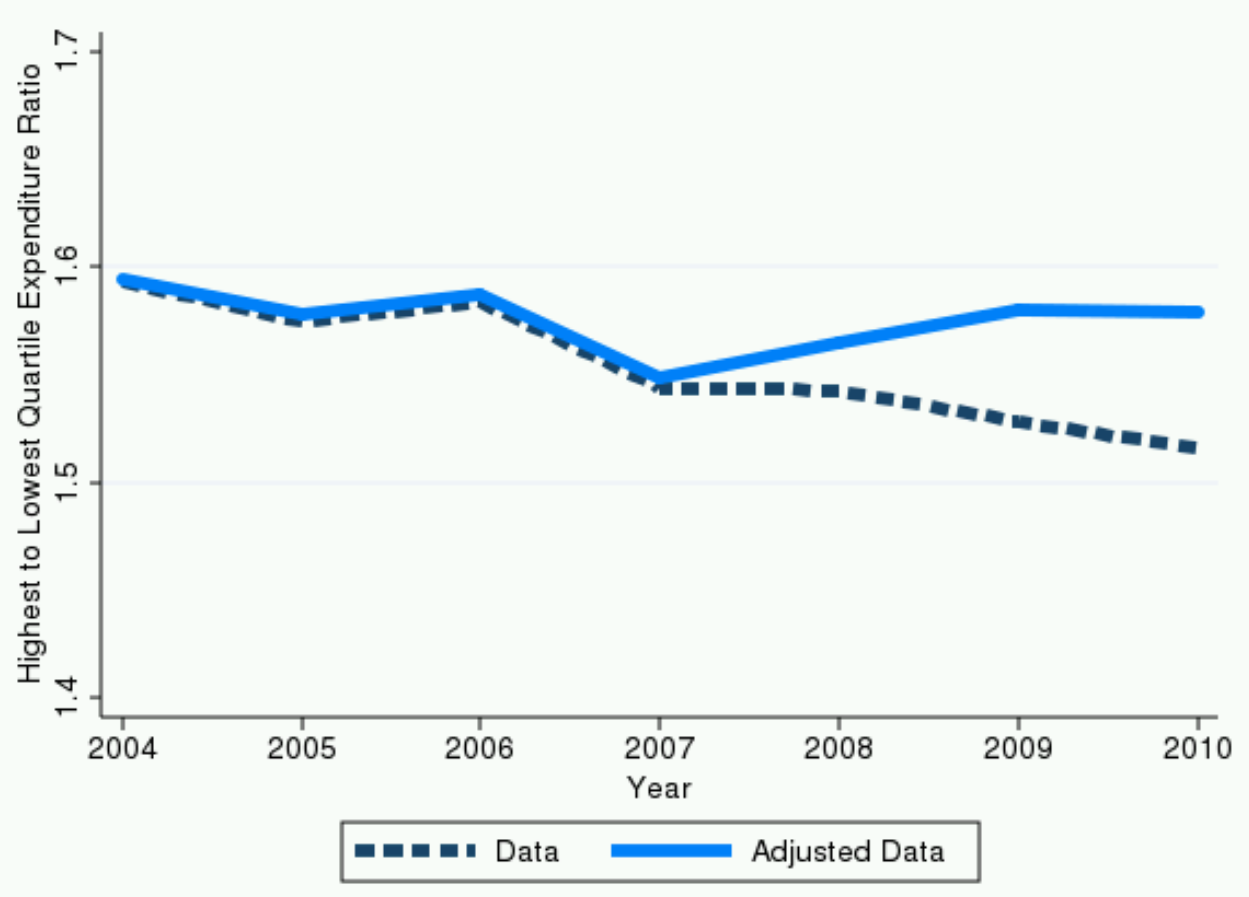

Note: The graph shows the change in expenditure ratio of highest to lowest quartile over time. Dotted line is expenditure ratio data calculated from Nielsen and solid line is the ratio adjusted by income-specific price indices.

the ratio of the highest quartile to the lowest quartile (i.e. 75/25) to examine its trend over time.

Figure 6 shows that the ratio of expenditures in our data (dotted line in the figure) follows a similar declining trajectory as consumption inequality described by Meyer and Sullivan (2013). The figure also shows that, when we adjust the total expenditures of each quartile using our income-specific price indices, the trajectory of the ratio flattens (solid line in the figure). Although our price indices are calculated only using information of goods available in the retail sector, this example illustrates that the patterns of consumption and income inequality could drastically change if one accounts for cost of living inflation differences.

Finally, mismeasurement in the cost of living has important implications de- 
termining the eligibility and allocation of public assistance programs particularly during bad times (Michael et al., 1995; Meyer and Sullivan, 2009). Our work indicates that in order to improve the allocation of public resources, the price adjustment for each group should use their own market basket, rather than using common price indices for everyone.

\section{Conclusion}

We document substantial differences in the cost of living inflation across income groups during the Great Recession. These differences, we argue, can be explained by their ability to adjust their shopping behavior to mitigate negative income shocks. Nonetheless, the gap in the cost of living inflation that we document persists beyond the Great Recession. Further research is necessary to find the extent of the cyclicality of this gap. In addition, our study also points toward the need for statistical agencies to produce income-specific price indices. While the production of these indices is likely to be costly, an accurate measurement of these indices will have, undoubtedly, important implications for the measurement of other real variables. 


\section{References}

Adelino, Manuel, Antoinette Schoar, and Felipe Severino, "House prices, collateral and self-employment," Technical Report, National Bureau of Economic Research 2013.

Aguiar, Mark A and Mark Bils, "Has consumption inequality mirrored income inequality?," Technical Report, National Bureau of Economic Research 2011.

Aguiar, Mark and Erik Hurst, "Life-Cycle Prices and Production," The American Economic Review, 2007, 97 (5), 1533-1559.

Attanasio, Orazio, Erik Hurst, and Luigi Pistaferri, "The Evolution of Income, Consumption, and Leisure Inequality in the US, 1980-2010," in "Improving the Measurement of Consumer Expenditures," University of Chicago Press, 2014.

Bartik, Timothy J, "Who benefits from state and local economic development policies?," Books from Upjohn Press, 1991.

Beraja, Martin, Erik Hurst, and Juan Ospina, "The Regional Evolution of Prices and Wages During the Great Recession," 2014.

Bhutta, Neil and Benjamin J Keys, "Interest rates and equity extraction during the housing boom," University of Chicago Kreisman Working Papers Series in Housing Law and Policy, 2014, (3).

BLS, Bureau of Labor Statistics handbook of methods, US Department of Labor, Bureau of Labor Statistics, 1997.

Boskin, Michael J, Toward a more accurate measure of the cost of living: final report to the Senate Finance Committee, Advisory Commission to Study the Consumer Price Index, 1996.

Bronnenberg, Bart J, Michael W Kruger, and Carl F Mela, "Database paper-The IRI marketing data set," Marketing Science, 2008, 27 (4), 745-748. 
Burstein, Ariel, Martin Eichenbaum, and Sergio Rebelo, "Large devaluations and the real exchange rate," Technical Report, National Bureau of Economic Research 2004.

Chevalier, Judith A and Anil K Kashyap, “Best prices,” Technical Report, National Bureau of Economic Research 2011.

Coibion, Olivier, Yuriy Gorodnichenko, and Gee Hee Hong, "The cyclicality of sales, regular and effective prices: Business cycle and policy implications," The American economic review, forthcoming.

Cutler, David M, Lawrence F Katz, David Card, and Robert E Hall, "Macroeconomic performance and the disadvantaged," Brookings Papers on Economic Activity, 1991, pp. 1-74.

Diewert, W Erwin, “Exact and superlative index numbers," Journal of econometrics, 1976, 4 (2), 115-145.

Driscoll, John C and Aart C Kraay, "Consistent covariance matrix estimation with spatially dependent panel data," Review of economics and statistics, 1998, 80 (4), 549-560.

Fisher, Jonathan, David S Johnson, and Timothy M Smeeding, "Inequality of income and consumption in the US: measuring the trends in inequality from 1984 to 2011 for the same individuals," Review of Income and Wealth, 2014.

Garner, Thesia I, David S Johnson, and Mary F Kokoski, "Experimental Consumer Price Index for the Poor, An," Monthly Lab. Rev., 1996, 119, 32.

Gilchrist, Simon, Raphael Schoenle, Jae Sim, and Egon Zakrajsek, "Inflation Dynamics during the Financial Crisis," 2013.

Griffith, Rachel, Ephraim Leibtag, Andrew Leicester, and Aviv Nevo, "Consumer shopping behavior: how much do consumers save?," The Journal of Economic Perspectives, 2009, 23 (2), 99-120. 
Hagemann, Robert P, "The variability of inflation rates across household types," journal of Money, Credit and Banking, 1982, pp. 494-510.

Handbury, Jessie, "Are Poor Cities Cheap for Everyone? Non-Homotheticity and the Cost of Living Across US Cities," 2013.

Heathcote, Jonathan, Fabrizio Perri, and Giovanni L Violante, "Unequal we stand: An empirical analysis of economic inequality in the United States, 1967-2006," Review of Economic Dynamics, 2010, 13 (1), 15-51.

Hobijn, Bart and David Lagakos, "Inflation inequality in the United States," review of income and Wealth, 2005, 51 (4), 581-606.

Kaplan, Greg and Guido Menzio, “The morphology of price dispersion,” Technical Report, National Bureau of Economic Research 2014.

Konüs, Alexander A, “The problem of the true index of the cost of living," Econometrica: Journal of the Econometric Society, 1939, pp. 10-29.

Krueger, Dirk and Fabrizio Perri, "Does income inequality lead to consumption inequality? Evidence and theory," The Review of Economic Studies, 2006, 73 (1), 163-193.

Kryvtsov, Oleksiy and Nicolas Vincent, "On the Importance of Sales for Aggregate Price Flexibility," Technical Report 2014.

McKenzie, David and Ernesto Schargrodsky, "Buying less, but shopping more: Changes in consumption patterns during a crisis," Bureau for Research and Economic Analysis of Development (BREAD) Working Paper, 2005, 92.

Meyer, Bruce D and James X Sullivan, "Five decades of consumption and income poverty," Technical Report, National Bureau of Economic Research 2009.

_ and _, "Consumption and Income Inequality and the Great Recession," American Economic Review, 2013, 103 (3), 178-83. 
Mian, Atif and Amir Sufi, "House Prices, Home Equity-Based Borrowing, and the US Household Leverage Crisis," The American Economic Review, 2011, pp. 2132-2156.

_ and _ , "House price gains and US household spending from 2002 to 2006," Technical Report, National Bureau of Economic Research 2014.

Michael, Robert T, "Variation Across Household in the Rate of Inflation,” 1979.

_, Constance F Citro et al., Measuring Poverty:: A New Approach, National Academies Press, 1995.

Nevo, Aviv and Arlene Wong, "The Elasticity of Substitution Between Time and Market Goods: Evidence from the Great Recession," in "2014 Meeting Papers” number 315 Society for Economic Dynamics 2014.

Petev, Ivaylo, Luigi Pistaferri, and Itay Saporta Eksten, "Consumption and the Great Recession: An Analysis of Trends, Perceptions, and Distributional Effects," 2011.

Saiz, Albert, "The geographic determinants of housing supply," The Quarterly Journal of Economics, 2010, 125 (3), 1253-1296.

Sato, Kazuo, "The ideal log-change index number," The Review of Economics and Statistics, 1976, pp. 223-228.

Stroebel, Johannes and Joseph Vavra, "House Prices, Local Demand, and Retail Prices," Available at SSRN 2500457, 2014.

Vartia, Yrjö O, "Ideal log-change index numbers," Scandinavian Journal of Statistics, 1976, pp. 121-126.

Watanabe, Tsutomu, David Weinstein, and Jessie Handbury, "How Much Do Official Price Indexes Tell Us About Inflation?," in “2014 Meeting Papers” number 73 Society for Economic Dynamics 2014. 


\section{Appendix}

Table 6: Distribution of Expenditures over Departments

\begin{tabular}{|c|c|c|c|c|}
\hline Code & Description & Product Groups & No. of UPCs & Expenditure \\
\hline 0 & $\begin{array}{l}\text { Health and } \\
\text { Beauty Aids }\end{array}$ & $\begin{array}{c}\text { baby care, cosmetics, cough \& cold } \\
\text { remedies, deodorant, hair care, oral } \\
\text { hygiene, pain remedies, skin care, } \\
\text { shaving }\end{array}$ & $17.4 \%$ & $10.2 \%$ \\
\hline 1 & Dry Grocery & $\begin{array}{l}\text { baby food, baking mixes, bottled } \\
\text { water, candy, carbonated beverages, } \\
\text { cereal, coffee, condiments, crackers, } \\
\text { pet food, prepared foods, snacks, } \\
\text { soup, canned vegetables }\end{array}$ & $29.4 \%$ & $39.3 \%$ \\
\hline 2 & $\begin{array}{l}\text { Frozen } \\
\text { Foods }\end{array}$ & $\begin{array}{l}\text { ice cream, frozen pizza, frozen } \\
\text { vegetables }\end{array}$ & $5.0 \%$ & $8.8 \%$ \\
\hline 3 & Dairy & cheese, eggs, yogurt & $3.2 \%$ & $9.0 \%$ \\
\hline 4 & Deli & & $1.7 \%$ & $2.0 \%$ \\
\hline 5 & $\begin{array}{l}\text { Packaged } \\
\text { Meat }\end{array}$ & & $1.3 \%$ & $3.2 \%$ \\
\hline 6 & $\begin{array}{c}\text { Fresh } \\
\text { Produce }\end{array}$ & & $1.0 \%$ & $2.6 \%$ \\
\hline 7 & $\begin{array}{l}\text { Non-Food } \\
\text { Grocery }\end{array}$ & $\begin{array}{l}\text { detergent, diapers, } \\
\text { fresheners/deodorizers, household } \\
\text { cleaners, laundry supplies, pet care }\end{array}$ & $11.2 \%$ & $12.9 \%$ \\
\hline 8 & Alcohol & beer, wine, liquor, coolers & $2.9 \%$ & $4.0 \%$ \\
\hline 9 & $\begin{array}{l}\text { General } \\
\text { Merchan- } \\
\text { dise }\end{array}$ & $\begin{array}{l}\text { batteries/flashlights, candles, } \\
\text { computer/electronic, cookware, } \\
\text { film/cameras, insecticides, lawn \& } \\
\text { garden, motor vehicle, office supplies }\end{array}$ & $26.9 \%$ & $8.0 \%$ \\
\hline
\end{tabular}

Note: The Nielsen Consumer panel is organized into departments, product groups, product modules, and UPC codes. Departments, product groups, and product modules are all Nielsen defined codes, while UPC codes are defined by manufacturers. The table reports the share of UPCs and expenditures in each department in the Nielsen Homescan. 
Table 7: Summary Statistics - Shopping Behavior by Income Group

\begin{tabular}{|c|c|c|c|c|}
\hline & Less than 25k & 25k to 50k & 50k to 100k & Over 100k \\
\hline \hline Exp. to Income & 0.26 & 0.10 & 0.06 & 0.04 \\
\hline Sales & 0.25 & 0.25 & 0.26 & 0.26 \\
\hline Coupons & 0.06 & 0.06 & 0.07 & 0.07 \\
\hline Generics & 0.19 & 0.17 & 0.15 & 0.14 \\
\hline Num. of Trips per Store & 4.37 & 4.11 & 3.79 & 3.58 \\
\hline Num. of Stores Visited & 8.67 & 9.28 & 9.63 & 9.76 \\
\hline Num. of Chains & 8.28 & 8.84 & 9.15 & 9.27 \\
\hline Num. of UPCs & 156.44 & 182.01 & 193.75 & 185.93 \\
\hline Num. of Categories & 90.98 & 103.40 & 109.07 & 105.21 \\
\hline Brands per Category & 3.44 & 3.61 & 3.69 & 3.73 \\
\hline
\end{tabular}

Note: The table reports the summary statistics of the shopping behavior of different income groups. The expenditure to income ratio is the average of the total expenditure of households in a given income group divided by their annual income. Sales is the share of expenditures of goods bought on sale. Coupons is the share of expenditures of goods bought with coupons. Generics is the share of expenditures on generic products. Number of trips per store is the average number of times a household visited a specific store. Number of stores (chains) is the average number of different stores (chains) at which the households report purchases in a given quarter. Number of UPCs (categories) is the average number of products (categories) purchased by the household every quarter. Brands per category indicate the average number of brands purchased by households of different income groups in a product module. All the variables, except the expenditure to income ratio are at the quarterly level. The source is the Nielsen Homescan from 2004-2010. 
Table 8: Expenditure Shares of Top 15 Firm

\begin{tabular}{|c|c|c|c|c|c|c|}
\hline \multirow[b]{2}{*}{ Rank } & \multirow[b]{2}{*}{ Firm } & \multirow[b]{2}{*}{$\begin{array}{l}\text { Total Ex- } \\
\text { penditure }\end{array}$} & \multicolumn{4}{|c|}{ Expenditure by Income Group } \\
\hline & & & Less than $25 \mathrm{k}$ & $25 \mathrm{k}$ to $50 \mathrm{k}$ & $50 \mathrm{k}$ to $100 \mathrm{k}$ & over $100 \mathrm{k}$ \\
\hline 1 & $\begin{array}{c}\text { Procter \& } \\
\text { Gamble }\end{array}$ & 9.16 & 7.85 & 8.61 & 9.53 & 10.53 \\
\hline 2 & Wal-Mart & 8.57 & 10.97 & 10.14 & 7.84 & 4.92 \\
\hline 3 & Nestle & 8.36 & 8.58 & 8.36 & 8.31 & 8.29 \\
\hline 4 & Kraft Foods & 5.64 & 5.48 & 5.59 & 5.72 & 5.68 \\
\hline 5 & $\begin{array}{l}\text { General } \\
\text { Mills }\end{array}$ & 5.14 & 4.65 & 4.98 & 5.33 & 5.39 \\
\hline 6 & Kroger & 4.95 & 5.31 & 5.19 & 4.84 & 4.41 \\
\hline 7 & $\begin{array}{l}\text { Conagra } \\
\text { Foods }\end{array}$ & 3.09 & 3.58 & 3.23 & 2.93 & 2.74 \\
\hline 8 & Pepsico & 2.97 & 3.32 & 3.14 & 2.91 & 2.44 \\
\hline 9 & Coca-Cola & 2.74 & 2.69 & 2.64 & 2.78 & 2.91 \\
\hline 10 & $\begin{array}{l}\text { Campbell } \\
\text { Soup }\end{array}$ & 2.36 & 2.43 & 2.40 & 2.34 & 2.27 \\
\hline 11 & Kellogg & 2.13 & 1.82 & 1.97 & 2.27 & 2.40 \\
\hline 12 & Costco & 2.09 & 0.87 & 1.46 & 2.38 & 3.79 \\
\hline 13 & $\begin{array}{l}\text { Unilever } \\
\text { Group }\end{array}$ & 2.09 & 1.89 & 2.04 & 2.16 & 2.17 \\
\hline 14 & Supervalu & 2.07 & 2.20 & 2.06 & 2.04 & 2.04 \\
\hline 15 & Heinz & 1.69 & 1.61 & 1.66 & 1.74 & 1.67 \\
\hline & Sum & 63.05 & 63.25 & 63.49 & 63.13 & 61.66 \\
\hline
\end{tabular}

Note: The table shows the expenditure shares by firms in the Homescan data. We link manufacturers and firms by merging the barcode provided by Nielsen and the information provided by GS1 US. The table shows the top 15 firms in terms of expenditure shares. 


\section{Figure 7: Household Purchase Unit Values and Household Income}

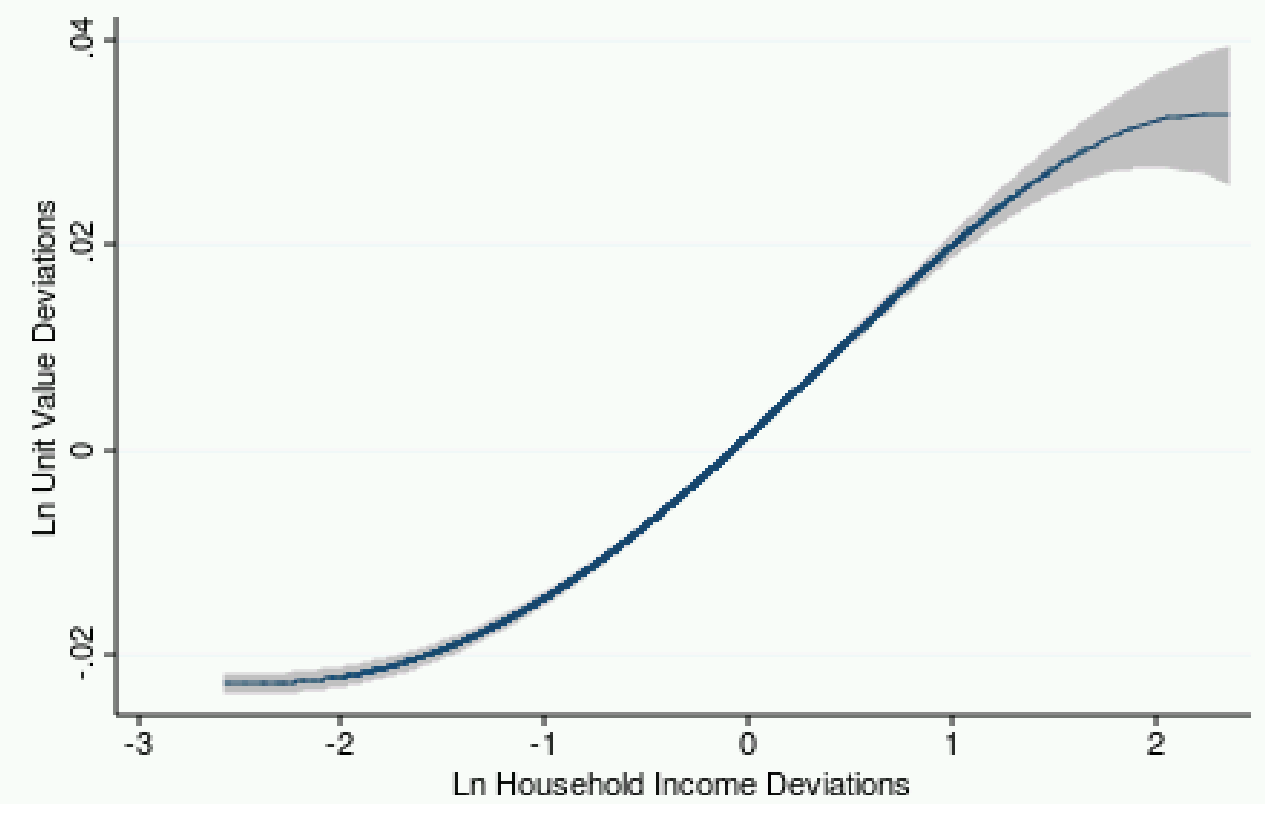

Note: The graph depicts the fractional polynomial prediction and the shaded areas indicate 95\% confidence intervals. The $y$-axis depicts the residuals of a regression of the log unit values on module-fips-chain-quarter fixed effects. The $\mathrm{x}$-axis depicts the residual regression of log household income on demographics controls. The standard errors are clustered at the module level. The bottom and top $1 \%$ on the $\mathrm{x}$-axis are excluded in the graph. Source: Nielsen Homescan 2007, number of observations 26,613,131 
Figure 8: Laspeyres, Paasche and Geometric Mean Indices (Nielsen Homescan)

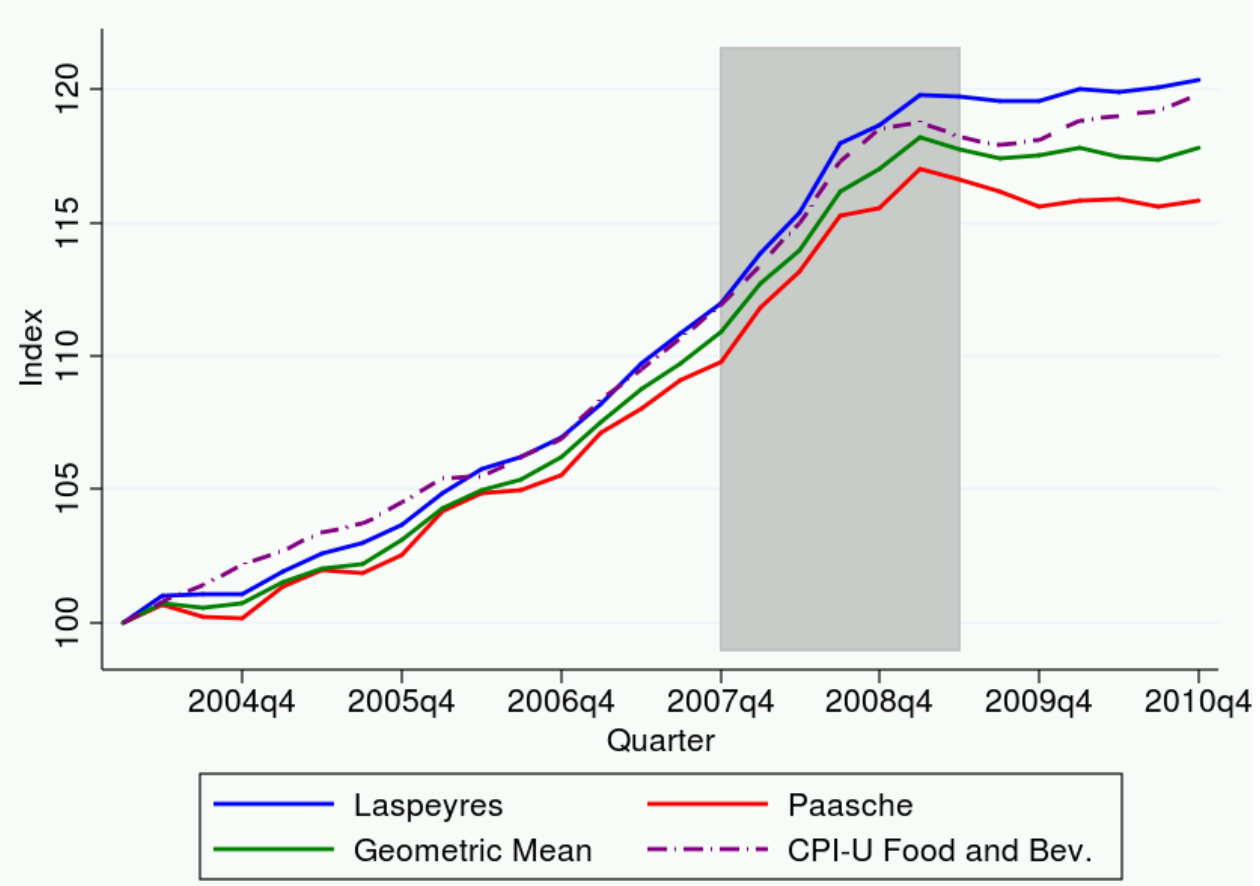

Note: The graph plots the Laspeyres, Paasche and geometric mean indices from the first quarter of 2004 to the last of 2010. For comparison the graph also plots the CPI-U Food and Beverage. The indices are calculated at the quarterly frequency and at the product module level. The shaded areas indicate periods designated as recessions by the National Bureau of Economic Research. The source is the Nielsen Homescan. 
Figure 9: Tornqvist, Fisher Ideal, and Sato-Vartia Indices (Nielsen Homescan)

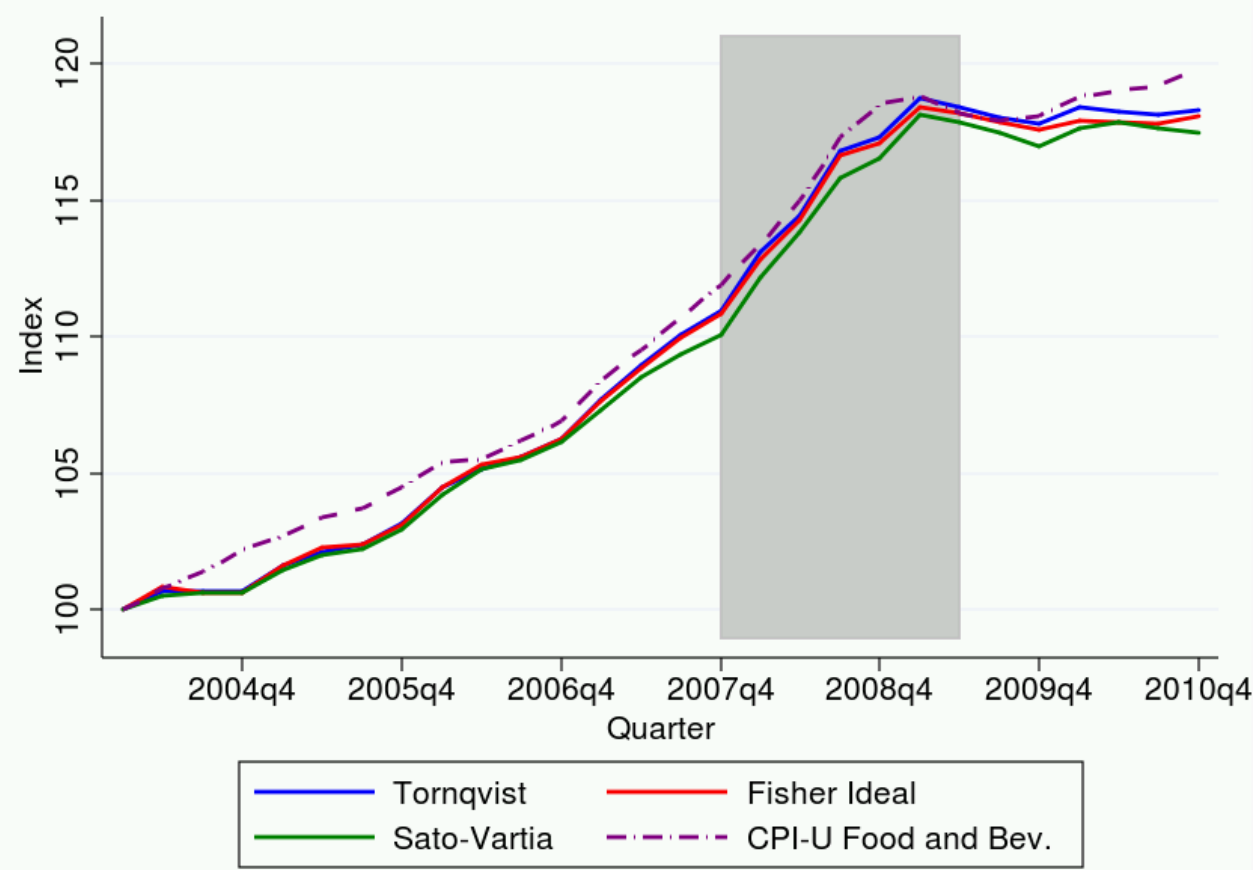

Note: The graph plots the Tornqvist, Fisher Ideal, and Sato-Vartia indices from the first quarter of 2004 to the last of 2010. For comparison the graph also plots the CPI-U Food and Beverage. The indices are calculated at the quarterly frequency and at the product module level. The shaded areas indicate periods designated as recessions by the National Bureau of Economic Research. The source is the Nielsen Homescan. 
Figure 10: Sato-Vartia Price Index with Income Specific Prices and Expenditure Weights (UPC Level)

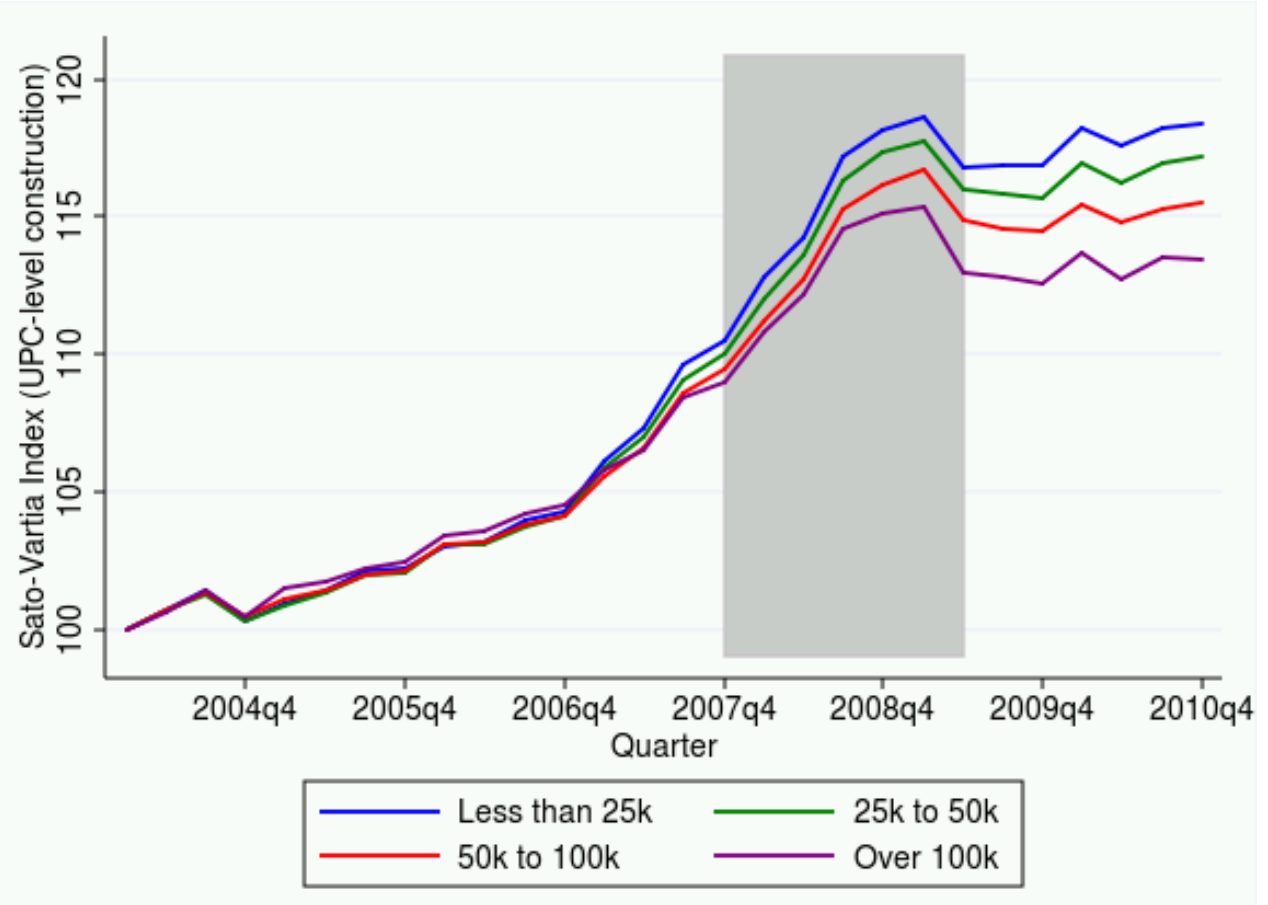

Note: The graph plots the Sato-Vartia index, from the first quarter of 2004 to the last of 2010, for each quartile of the income distribution. The expenditure weights and the prices are income specific. The indices are calculated at the quarterly frequency and at the UPC level. We kept a balanced panel of UPCs to calculate the indices. The shaded areas indicate periods designated as recessions by the National Bureau of Economic Research. The source is the Nielsen Homescan. 
Figure 11: Chained Sato-Vartia Price Index with Income Specific Prices and Expenditure Weights (UPC Level)

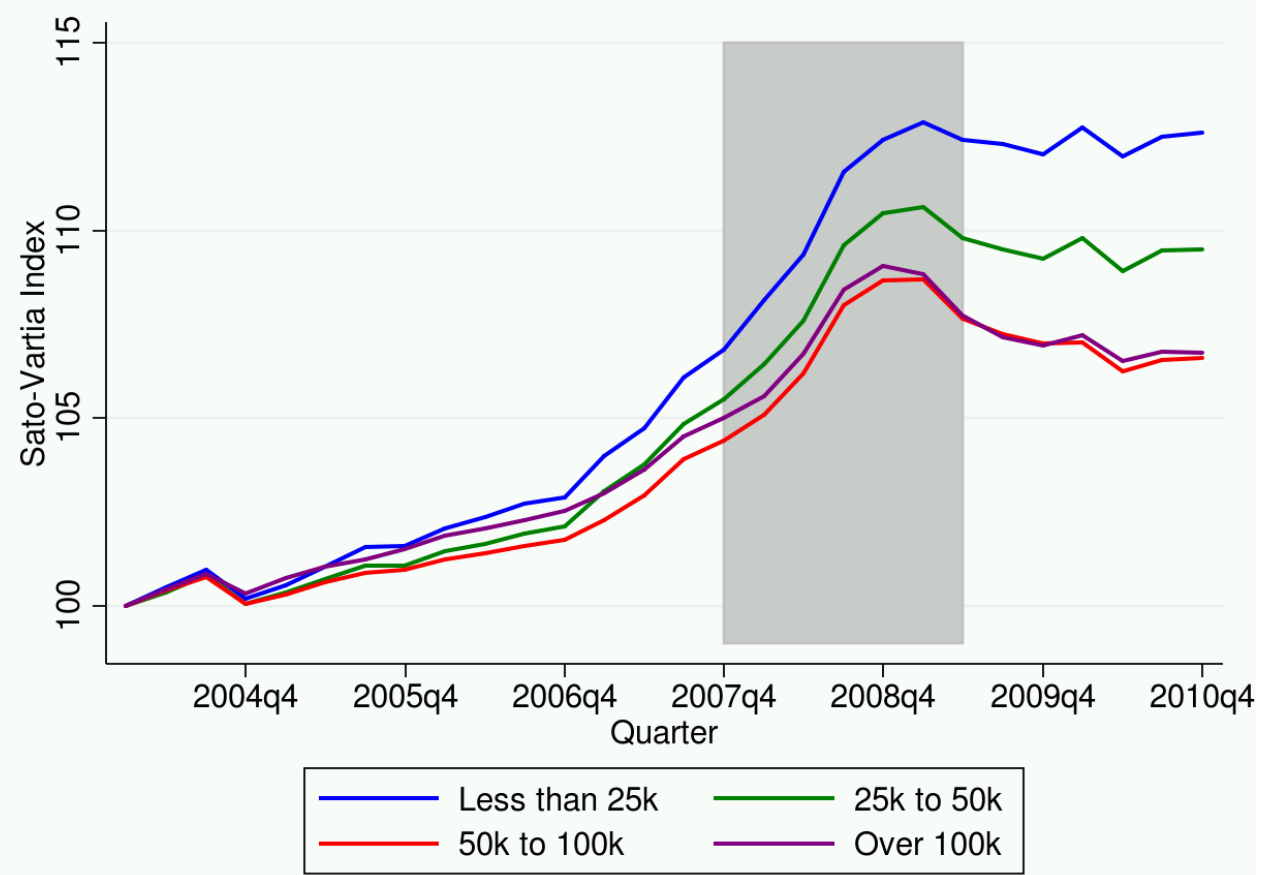

Note: The graph plots the chained Sato-Vartia index, from the first quarter of 2004 to the last of 2010, for each quartile of the income distribution. The expenditure weights and the prices are income specific. The indices are calculated at the quarterly frequency and at the UPC level. The shaded areas indicate periods designated as recessions by the National Bureau of Economic Research. The source is the Nielsen Homescan. 
Figure 12: Laspeyres Price Index with Income Specific Expenditure Weights

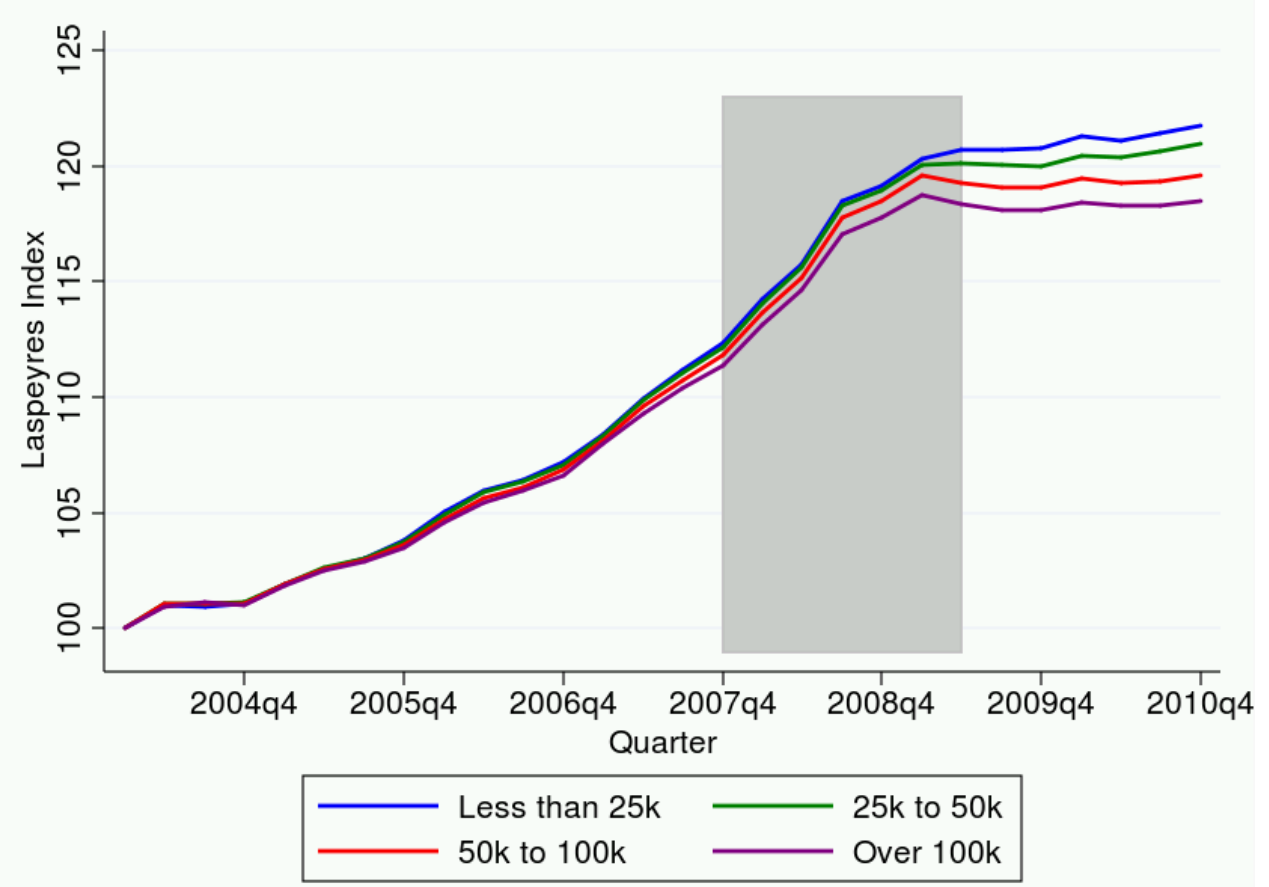

Note: The graph plots the Laspeyres index, from the first quarter of 2004 to the last of 2010, for each quartile of the income distribution. The expenditure weights are income specific. The indices are calculated at the quarterly frequency and at the product module level. The shaded areas indicate periods designated as recessions by the National Bureau of Economic Research. The source is the Nielsen Homescan. 
Figure 13: Laspeyres Price Index with Income Specific Prices and Expenditure Weights

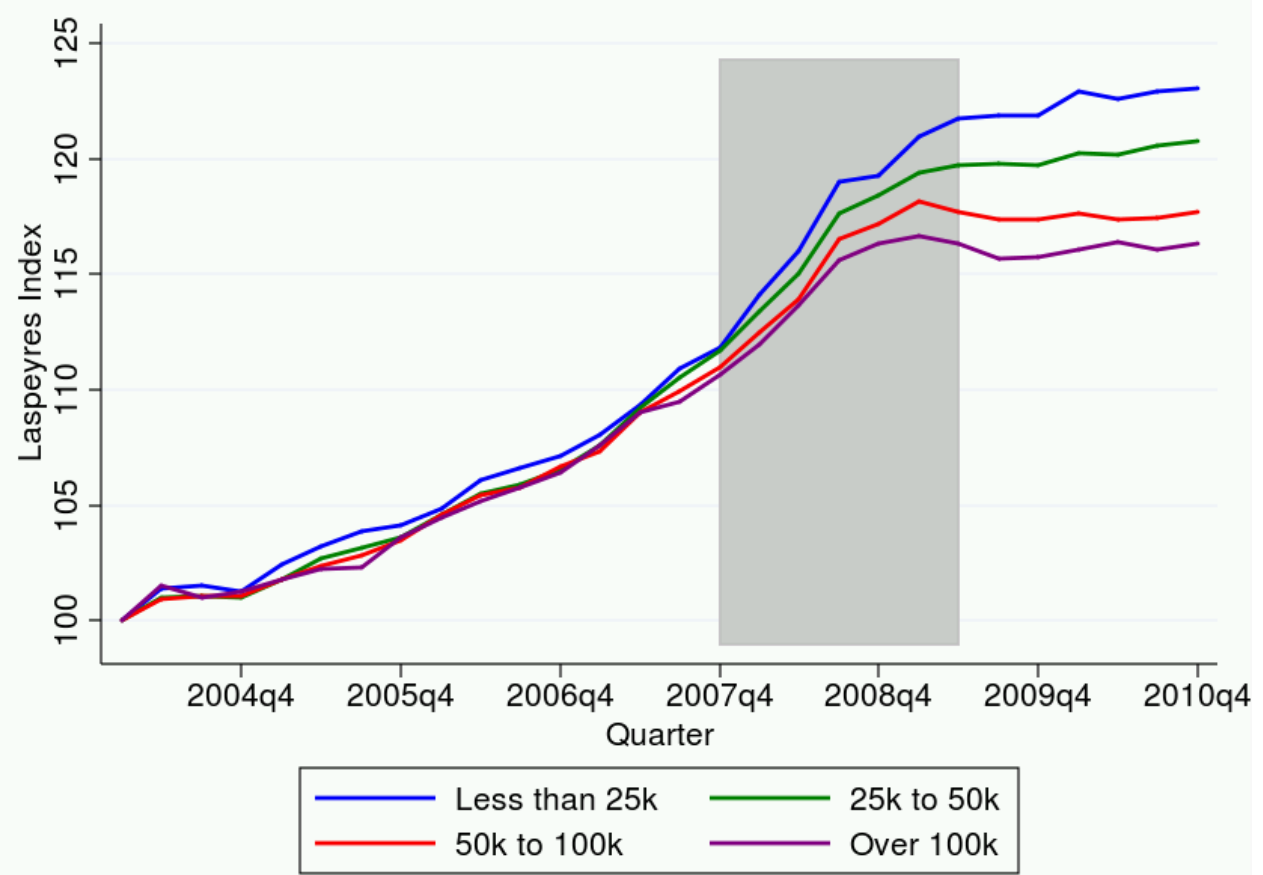

Note: The graph plots the Laspeyres index, from the first quarter of 2004 to the last of 2010, for each quartile of the income distribution. The expenditure weights and the prices are income specific. The indices are calculated at the quarterly frequency and at the product module level. The shaded areas indicate periods designated as recessions by the National Bureau of Economic Research. The source is the Nielsen Homescan. 
Figure 14: Unemployment Rate: Chicago Metropolitan Area

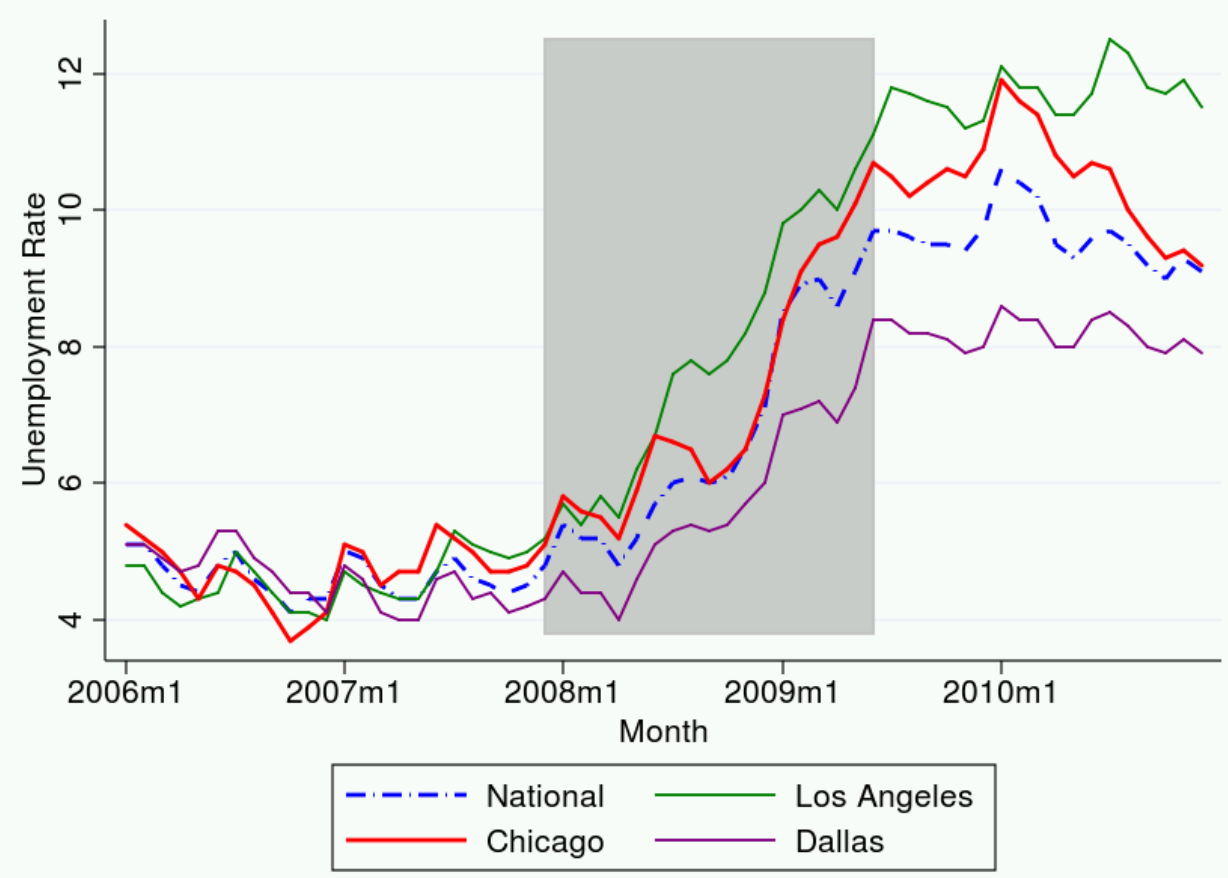

Note: The graph plots average unemployment rate for different cities. The shaded areas indicate periods designated as recessions by the National Bureau of Economic Research. The source is the Bureau of Labor Statistics. 